TITLE:

\title{
Numerical modelling of river embankment failure due to overtopping flow considering infiltration effects
}

\section{$\operatorname{AUTHOR}(S):$}

Mizutani, Hideaki; Nakagawa, Hajime; Yoden, Toshiaki; Kawaike, Kenji; Zhang, Hao

\section{CITATION:}

Mizutani, Hideaki ... [et al]. Numerical modelling of river embankment failure due to overtopping flow considering infiltration effects. Journal of Hydraulic Research 2013, 51(6): 681-695

\section{ISSUE DATE:}

2013-09-10

URL:

http://hdl.handle.net/2433/197267

\section{RIGHT:}

This is an Accepted Manuscript of an article published by Taylor \& Francis in Journal of Hydraulic Research on 2013, available online: http://www.tandfonline.com/10.1080/00221686.2013.812151; この論文は出版社版でありません。弓 用の際には出版社版をご確認ご利用ください。; This is not the published version. Please cite only the published version. 


\section{Numerical Modeling of River Embankment Failure Due to Overtopping Flow Considering Infiltration Effects}

Hideaki MIZUTANI, (IAHR Member), Assistant professor, Disaster Prevention Research Institute, Kyoto University, Yoko-oji, Fushimi-ku, Kyoto 612-8235, Japan

Email:mizutani@uh31.dpri.kyoto-u.ac.jp

Hajime NAKAGAWA, (IAHR Member), Professor, Disaster Prevention Research Institute, Kyoto University, Yoko-oji, Fushimi-ku, Kyoto 612-8235, Japan

Email:nakagawa@uh31.dpri.kyoto-u.ac.jp

Toshiaki YODEN, Group manager of river engineering group, NEWJEC Inc., Honjo-Hidashi, Kita-ku, Osaka 531-0074, Japan

Email:yodents@newjec.co.jp

Kenji KAWAIKE, (IAHR Member), Associate professor, Disaster Prevention Research Institute, Kyoto University, Yoko-oji, Fushimi-ku, Kyoto 612-8235, Japan

Email: kawaike@uh31.dpri.kyoto-u.ac.jp

Hao ZHANG, (IAHR Member), Assistant professor, Disaster Prevention Research Institute, Kyoto University, Yoko-oji, Fushimi-ku, Kyoto 612-8235, Japan

Email: zhang@uh31.dpri.kyoto-u.ac.jp 


\title{
Numerical Modeling of River Embankment Failure Due to Overtopping Flow Considering Infiltration Effects
}

\begin{abstract}
This study conducted laboratory experiments and numerical simulations of river embankment failure due to overtopping flow with different sediment sizes and different saturation conditions of embankment body. The influences of saturation and sediment size of embankment materials on the erosion process were discussed based on the results of the laboratory experiments, and a numerical model was developed to simulate the erosion process of embankments by flow overtopping. The developed model introduced the effects of infiltration process and resisting shear stress due to suction of unsaturated sediment as a new expression. To simulate the embankment erosion phenomenon, the numerical model consisted of four modules: two-dimensional shallow-water flow, seepage flow, sediment transport using a non-equilibrium model framework, and two-dimensional slope stability. The reproducibility of the developed model was tested using experimental data on embankment erosion. The numerical results of progressive embankment erosion well agreed with the results of the sandy river embankment experiments.
\end{abstract}

Keywords: erosion due to overtopping flow, river embankment, seepage flow, suction, unsaturated soil

\section{Introduction}

Annual precipitation in Japan is approximately twice the world average of $810 \mathrm{~mm}$, and most regions of Japan are classified as high rainfall zones. In particular, annual precipitation in the south Kyushu region, the south Shikoku region, the south Kinki region, Gifu prefecture, and the Hokuriku region exceeds 2,000 mm; hence, floods occur frequently. Countermeasures for flood inundation, quick rises in water levels, and river embankment failure are long-term issues in Japan. The river embankment (levee or dike) is the last fort against river flooding to protect lives and to prevent property damage. Climate change will probably lead to an increase in heavy rainfall events and rises in river water levels that exceed their design. Therefore, reinforcement of river embankments plays a larger role in disaster prevention than ever before.

In-depth knowledge of the mechanism of embankment failure is still lacking. To understand the failure process of river embankment due to flow overtopping, some experimental studies have been carried out by previous researchers (Powledge et al. 1989, Chinnarasri et al. 2003, Pickert et al. 2011). One of the first great contributions to research on embankment erosion due to overflow was made by Powledge et al. (1989). They presented three main hydraulic and erosion zones and discussed various hydraulic aspects of 
embankment overtopping flow. Chinnarasri et al. (2003) discussed flow patterns and progressive damage of embankment overtopping. Pickert et al. (2011) pointed out that apparent cohesion due to pore-water pressure influences the stability of breach side slopes. Several numerical simulations have also been conducted on the phenomenon of embankment failure due to overtopping flow. However, problems with predictions using the existing physical-based numerical models need further investigation. The accuracy of the simulated results of existing embankment failure models is probably inadequate at present for a simulation tool to make predictions and to consider countermeasures. In particular, the numerical models could not sufficiently reproduce the time variations in the shape of embankments-namely, the progressive damage of embankments under various sediment sizes and saturation conditions.

Many difficulties must be resolved to develop a numerical model of embankment failure due to overtopping flow. The process of embankment breaching by overtopping is very complex because it involves mutually dependent interactions between fluvial hydraulics, sediment transport, infiltration, and embankment stability on a steep bed slope. Erosion occurs primarily on the backside slope of an embankment where most soils are in an unsaturated condition. In some circumstances, water in unsaturated soils form menisci between particles. The meniscus water clinging to the contact point of soil particles connects the soil particles tightly together. Surface tensions due to meniscus water and interface curvature give rise to a difference between pore-water pressure and pore-air pressure that is generally equated to matric suction. The inter-particle force between two adjacent particles is generated by the surface tension of pore-water and suction, and an increase in the interparticle force activates shear strength against erosion. Therefore, the erosion rate for unsaturated soils may be quite different from the erosion rate for saturated soils like a riverbed. Furthermore, the inter-particle force characteristically depends on the degree of soil saturation. To calculate more precisely the erosion process on unsaturated soils, considering the resisting shear stress due to suction is important, and it is also important to consider the temporal saturation changes in the embankment body, especially the surface infiltration process from overtopping flow. The necessity of considering the infiltration of water inside the embankment is one reason why developing a universal numerical model has been difficult thus far.

Several previous studies attempted to use numerical simulation to reproduce the phenomenon of embankment erosion and failure due to overtopping flow. For example, Tingsanchali and Chinnarasri (2001) developed a one-dimensional numerical model that considered circular slope stability for embankment failure and compared the simulated results with the experimental results. They indicated the importance of the estimation of the erosion rate calculated using a sediment transport formula. Several sediment transport models were 
applied to their model, and the coefficients of the sediment transport model were adjusted by trial and error to fit their experimental data and to investigate the effect of coefficients related to the erosion rate. Gotoh et al. (2002; 2008) introduced the moving particle semi-implicit (MPS) method, which is classified in a gridless numerical model, a numerical model of embankment erosion that avoids numerical diffusion in water surface tracking. The pick-up sediments from the embankment surface were calculated using an advanced method-a submodel that considers the effect of the velocity component perpendicular to the slope. However, this sophisticated numerical model also faced a problem related to disagreement of the erosion rate and used the erosion rate based on data from laboratory experiments to reproduce the phenomenon of the experiments and to focus on other topics in their study. Wang and Bowles (2007) developed an embankment breach model using one-dimensional flow and a three-dimensional slope stability model, and indicated the importance of mechanisms of local sliding during the progressive failure process. Their simulations also adjusted several soil parameters, including cohesion, internal friction angle, and erodibility of the embankment soil, to fit the experimental results.

As previously described, several numerical simulations have been conducted regarding embankment erosion; however, problems remain regarding the effects of infiltration on erosion due to overtopping flow. The infiltration process on the backside slope is very complex because the surface erosion and the saturation conditions on an embankment surface are continually and simultaneously changing due to the infiltration of overtopping flow. Indeed, solving this problem is not easy; we had no choice but to individually adjust the coefficients simply related to erodibility to fit the results of the experiments to focus on other topics because of a lack of understanding of erosion at different saturation levels. Thus, we have postponed or ignored the modeling the effects of the physical process of infiltration, such as the difference in erosion in saturated and unsaturated soil. Therefore, unfortunately, whether a numerical model has already been developed that could serve as a powerful tool for prediction and practical use is difficult to say at present.

Furthermore, we must remember that many embankments were built from cohesive material. Cohesive sediments behave quite differently than non-cohesive sediments, and the erosion rate of cohesive sediments is difficult to predict considering the physical properties at present. Therefore, the early stage of this study focused on the erosion of embankments made by non-cohesive material, leaving the subject of cohesive sediment for future research. We will contemplate developing a numerical model of embankment erosion made with cohesive materials that considers the infiltration effects after the development of a model for noncohesive materials. We believe that it is important to embark on an investigation of noncohesive embankments to allow for a better understanding and clarification of the effects of infiltration on the erosion of non-cohesive materials before investigating the complicated 
phenomenon of erosion under the coexistence condition of infiltration and the cohesion effects on embankment surface. In Bangladesh and for the middle basing of some rivers in Japan, many embankments are made from non-cohesive materials; hence, the development of an erosion model for non-cohesive embankments is as important as developing a model for cohesive material embankments.

This paper investigates the erosion process of embankments due to overtopping flow through an experimental method using different size of non-cohesive sediments and relatively uniform sediments. Special attention is paid to the influence of the differences in sediment size and degree of saturation in an embankment dam body on the erosion process. Furthermore, the experimental results were also utilized to test the newly developed and proposed model in this study. Another purpose of this research is to develop a new numerical model that can simulate the river embankment erosion process and that considers the effects of infiltration on surface erosion without adjusting the coefficients related to erodibility in the erosion rate formula.

\section{Numerical model of embankment erosion due to overtopping flow}

A numerical model for predicting erosion due to overtopping flow at a river embankment was developed by combining four modules: surface flow, seepage flow, sediment transport, and slope failure. The novelty of this study is in the combination of these modules to reproduce the complicated embankment failure process. Figure 1 shows a conceptual diagram of the interaction among the modules. There are many interactions among the modules, and the highlight of the present model is its estimation of the erosion rate by considering that the effect of resisting shear stress due to suction depends on saturation conditions on the embankment surface, which is calculated using the result from the seepage flow module. In order to focus on the improvement in the treatment of the surface erosion process, the developed model was reduced to vertical two-dimensional calculations in seepage and erosion modules; however, the horizontal 2D flow model was introduced to consider the extensibility for our future work. Therefore, the present model cannot reproduce horizontal 2D phenomena, such as an expansion process of breach of embankment and a complicated failure process due to 3D flow. Detailed descriptions of each module are provided below.

\subsection{Calculation of seepage flow inside an embankment}

The change in moisture content and pore-water pressure through unsaturated-saturated soils of the embankment dam is computed using Richards' equation: 


$$
C(\psi) \frac{\partial \psi}{\partial t}=\frac{\partial}{\partial x}\left(K_{x} \frac{\partial \psi}{\partial x}\right)+\frac{\partial}{\partial z}\left(K_{z} \frac{\partial \psi}{\partial z}+1\right)
$$

where $\psi$ is the water pressure head, $K_{x}$ and $K_{z}$ are the hydraulic conductivity in the $x$ and $z$ directions, $C(\psi)\left(=\partial \theta_{w} / \partial \psi\right)$ is the specific moisture capacity, $\theta_{w}$ is the volumetric water content of the soil, $x$ is the horizontal spatial coordinate, $z$ is the vertical spatial coordinate taken as positive upwards, and $t$ is time.

To solve Eq. (1), the relationship between the water storage coefficient and the coefficient of permeability must be understood. In this study, the seepage flow analyses in the embankment dam are conducted by inserting the widely-used constitutive relationships given by Van Genuchten (1980) as follows:

$$
\begin{aligned}
& S_{e}=\frac{\theta_{w}-\theta_{r}}{\theta_{s}-\theta_{r}}=\left\{\begin{array}{cr}
1 /\left(1+|\alpha \psi|^{\eta}\right)^{m} & \text { if }(\psi<0) \\
1 & f(\psi \geq 0)
\end{array}\right. \\
& K=\left\{\begin{array}{cr}
K_{s} S_{e}^{0.5}\left[1+\left(1-S_{e}^{1 / m}\right)^{m}\right]^{2} & \text { if }(\psi<0) \\
K_{s} & f(\psi \geq 0)
\end{array}\right. \\
& C=\left\{\begin{array}{cc}
\left\{\left\{1+(|\alpha \psi|)^{\eta}\right\}^{-m-1} \eta(|\alpha \psi|)^{\eta-1} \alpha\left(\theta_{s}-\theta_{r}\right)\right. & \text { if }(\psi<0) \\
0 & f(\psi \geq 0)
\end{array}\right.
\end{aligned}
$$

where $S_{e}$ is the effective saturation; $\theta_{s}$ and $\theta_{r}$ are the saturated and residual moisture content of the sediments, respectively; $\alpha$ and $\eta$ are the parameters related to the matric potential of the soil and are determined using a curve-fitting of the soil-water retention curve; $K$ and $K_{s}$ are the unsaturated and saturated hydraulic conductivity; and $m=1-\eta^{-1}$. The equations for the seepage flow model are solved using the line successive over relaxation (LSOR) scheme with implicit iterative finite difference schemes.

\subsection{Hydraulics calculation}

The governing equations of the flow module are the depth-averaged two-dimensional equations and the continuity equation of the flow, which are described as follows:

$$
\begin{gathered}
\frac{\partial u}{\partial t}+u \frac{\partial u}{\partial x}+v \frac{\partial u}{\partial y}=-g \frac{\partial H}{\partial x}-\frac{\tau_{b x}}{\rho h}+\frac{\partial}{\partial x}\left(\frac{\tau_{x x}}{\rho}\right)+\frac{\partial}{\partial y}\left(\frac{\tau_{x y}}{\rho}\right) \\
\frac{\partial v}{\partial t}+u \frac{\partial v}{\partial x}+v \frac{\partial v}{\partial y}=-g \frac{\partial H}{\partial y}-\frac{\tau_{b y}}{\rho h}+\frac{\partial}{\partial x}\left(\frac{\tau_{x y}}{\rho}\right)+\frac{\partial}{\partial y}\left(\frac{\tau_{y y}}{\rho}\right) \\
\frac{\partial h}{\partial t}+\frac{\partial(u h)}{\partial x}+\frac{\partial(v h)}{\partial y}=0
\end{gathered}
$$


where $u$ and $v$ are the flow velocity components in the $x$ and $y$ directions, $g$ is the acceleration of gravity, $H$ is the water level, $h$ is the flow depth, $\rho$ is water density, and $\tau_{b x}$ and $\tau_{b y}$ are the bottom shear stresses in the $x$ and $y$ directions. The shear forces due to turbulence, $\tau_{x x}, \tau_{y y}, \tau_{x y}$, are described as follows:

$$
\frac{\tau_{x x}}{\rho}=2 \varepsilon \frac{\partial u}{\partial x}, \quad \frac{\tau_{y y}}{\rho}=2 \varepsilon \frac{\partial v}{\partial y}, \quad \frac{\tau_{x y}}{\rho}=\varepsilon\left(\frac{\partial u}{\partial y}+\frac{\partial v}{\partial x}\right)
$$

where $\varepsilon$ is the eddy viscosity $\left(\varepsilon=\kappa u_{*} h / 6, \kappa\right.$ is von Karman's constant, and $u_{*}$ is friction velocity). The bottom shear stresses are expressed as follows:

$$
\begin{gathered}
\tau_{b x}=\rho g n^{2} u \sqrt{u^{2}+v^{2}} / h^{1 / 3} \\
\tau_{b y}=\rho g n^{2} v \sqrt{u^{2}+v^{2}} / h^{1 / 3}
\end{gathered}
$$

where $n$ is the Manning coefficient. The discretized equations of the flow module are solved using the SIMPLE revised (SIMPLER) scheme, a widely-used scheme that utilizes the relationships between velocity and pressure corrections to enforce mass conservation (Patankar 1980).

\subsection{Calculation of erosion and deposition}

The overtopping surface flow erodes the backside slope of an embankment; the shape of the embankment dam changes; and the sediments picked up from its surface are transported downstream and deposited at a distance from the embankment. This process is strongly affected not only by surface flow but also by a steep slope. To consider in numerical simulation the effect of the slope, which is steep and changes over time during the erosion and deposition process, this study introduced the framework for a non-equilibrium sediment transport model as suggested by Nagata et al. (2005) into the numerical model of river embankment breach. Furthermore, an improved pick-up rate formula was introduced, and the thickness of the surface saturated soil layer and the unsaturated soil below the surface are considered in the erosion rate estimation to simulate more accurately the embankment erosion process.

During the erosion process caused by overtopping flow, water flow over the backside slope exceeds the critical shear stress of the embankment material, which is estimated under a saturated soil condition, and the water depth is shallow given the steep slope. Several numerical studies carried out numerical simulations of embankment and earth dam erosion using simply the sediment transport formula, which is widely used to calculate riverbed variations (e.g., Tingsanchali and Chinnarasri 2001, Faeh 2007). However, the simulated 
erosion rates tend to be overestimated in such conditions. In addition, the dam material consists of relatively fine sediments compared to riverbed conditions. Because the shear strength effect from suction exists on unsaturated soil, the possibility exists that the erosion rate is larger in large sediment conditions compared with small sediment conditions (Nakagawa et al. 2011). Therefore, most current sediment transport formulas used in the simulation of riverbed variations are not applicable to embankment erosion from overtopping flow without a modification.

This study attempted to introduce the effect of resisting shear stress due to suction as an increase in resisting shear stress in a pick-up rate formula. It also attempted to simulate laboratory experiments to solve the problem.

\subsubsection{Calculation of pickup volume}

The volume of sediment being picked up from the embankment surface is estimated using the following equation:

$$
V_{p}=\left[\left(A_{3} d\right) / A_{2}\right] p_{s} S_{p}
$$

where $V_{p}$ is sediment pick-up volume per unit time, $p_{s}$ is pick-up rate, $d$ is the diameter of sediment particles, $S_{p}$ is the projected area of the computational mesh onto the horizontal plane, and $A_{2}, A_{3}$ are the shape coefficients of sediment particles for 2D and 3D geometrical properties ( $=\pi / 4$ and $\pi / 6$, respectively). The pick-up volume can be converted into the erosion rate $\left(E_{r}=V_{p} / S_{p}\right)$.

The pick-up rate of sediment particles from the embankment surface is calculated using the following formula proposed by Nakagawa et al. (1985), and we introduced the effect of resisting shear stress due to suction in this study.

$$
p_{s} \sqrt{\frac{d}{(\sigma / \rho-1) g}}=F_{0} G_{*} \tau_{*}\left(1-\frac{k_{p} \phi_{b} \tau_{* c}+\tau_{* s u c}}{\tau_{*}}\right)^{m_{p}}
$$

in which

$$
\begin{gathered}
G_{*}=\frac{\cos \psi_{b}+k_{L} \mu_{s}}{1+k_{L} \mu_{s}} \\
\phi_{b}=\frac{\mu_{s} \cos \theta_{b}-\sin \theta_{b} \cos \alpha_{d}}{\cos \psi_{b}+k_{L} \mu_{s}} \frac{1+k_{L} \mu_{s}}{\mu_{s}}
\end{gathered}
$$

where $\sigma$ is the density of sediment $(\sigma / \rho=2.65) ; \tau_{*}, \tau_{*_{c}}$ are the dimensionless shear stress 
and critical shear stress for sediments; $F_{0}, k_{p}$, and $m_{p}$ are constants $(=0.03,0.7$, and 3.0, respectively) as suggested by Nakagawa et al. (1985) for saturated bed conditions; $G_{*}$ is the coefficient that accounts for the direction deviation between near the bed velocity and sediment movement direction; $\psi_{b}$ is the angle between the near bed velocity and the sediment movement direction; $\phi_{b}$ is the coefficient that accounts for the local bed-slope and the direction deviation between the maximum local bed slope and the sediment movement direction; $\mu_{s}$ is the static friction factor $(=0.7) ; k_{L}$ is the ratio of lift force to drag force (=0.85); $\theta_{b}$ is the local bed-slope; $\alpha_{d}$ is the angle between the maximum local bed-slope and sediment movement direction; and $\tau_{*_{s u c}}$ is dimensionless shear stress due to suction, which is described below.

This study attempted to introduce the effect of resisting shear stress due to suction on critical shear stress in a manner similar to Nakagawa et al. (2011) for the pick-up rate formula. The resisting shear stress due to suction for unsaturated soil was calculated using the relationship proposed by Vanapalli et al. (1996), wherein the increase in the resisting shear stress due to suction can be expressed as follows:

$$
\tau_{\text {suc }}=\left|p_{a}-p_{w}\left(\frac{\theta_{w}-\theta_{r}}{\theta_{s}-\theta_{r}}\right) \tan \phi=\rho g\right| \psi\left(\frac{\theta_{w}-\theta_{r}}{\theta_{s}-\theta_{r}}\right) \tan \phi
$$

where $p_{a}$ is the pore-air pressure, $p_{w}$ is the pore-water pressure, $p_{a}-p_{w}$ is the matric suction, and $\phi$ is the effective angle of internal friction. Egiazaroff (1965) derived an expression for the dimensionless critical shear stress of sediment, which is part of a mixture of sediments. To simulate the erosion process on unsaturated soils of an embankment, we introduced the resisting shear stress due to suction into the critical condition for sediment movement. In the critical condition of sediment movement, the drag force $\left(R_{T}\right)$ and friction force $(F)$, which are balanced, are described as follows:

$$
\begin{gathered}
R_{T}=\frac{\rho}{2} C_{D} u_{b}^{2} A_{2} d^{2} \\
F=\frac{\pi}{6} d^{3}(\sigma-\rho) g f+\tau_{\text {suc }} A_{2} d^{2}
\end{gathered}
$$

where $C_{D}$ is the drag coefficient $(=0.4), u_{b}$ is flow velocity acting on a sediment particle, and $f$ is the friction coefficient $(=\tan \phi)$. The following equation was derived under the critical condition $\left(R_{T}=F\right)$ :

$$
\frac{u_{b}^{2}}{(\sigma / \rho-1) g d}=\frac{4 f}{3 C_{D}}+\frac{2 \tau_{\text {suc }}}{C_{D} \rho(\sigma / \rho-1) g d}
$$


The flow velocity of which the location is ad from the level of the embankment surface is expressed using an equivalent height of sediment roughness, which is equal to the mean diameter of sediment $\left(d_{m}\right)$, as follows:

$$
\frac{u_{b}^{2}}{u_{*}}=5.75 \log _{10}\left(\frac{30.2 a d}{d_{m}}\right)
$$

where $a=0.63$ and $f=1.0$ are used (Egiazaroff 1965), and $u_{*}$ is equal to $u_{*_{c}}^{\prime}$ under the critical condition. Adding the resisting shear stress to the friction force enables the Egiazaroff formula to be expressed using the following new equation:

$$
\begin{aligned}
\frac{u_{*_{c}}^{\prime 2}}{(\sigma / \rho-1) g d}= & \frac{4}{3 C_{D}} \frac{1}{\left[5.75 \log _{10} 19\left(d / d_{m}\right)\right]^{2}} \\
& +\frac{2 \tau_{\text {suc }}}{C_{D} \rho(\sigma / \rho-1) g d\left[5.75 \log _{10} 19\left(d / d_{m}\right)\right]^{2}}
\end{aligned}
$$

in which the second term on the right-hand side is the contribution of resisting shear stress due to suction. Because our laboratory experiments were carried out under uniform sediments, the dimensionless resisting shear stress in Eq. (20) is expressed as follows:

$$
\tau_{\text {suc* }}=\frac{2 \tau_{\text {suc }}}{C_{D} \rho(\sigma / \rho-1) g d\left[5.75 \log _{10} 19\right]^{2}}
$$

The dimensionless critical shear stress was calculated using the Iwagaki formula (1956), and the dimensionless resisting shear stress due to suction was added to Eq.(12).

\subsubsection{Treatment of surface erosion}

On the backside slope of an embankment, infiltration and erosion processes occur quasisimultaneously from overtopping flow, and the erosion process due to overtopping flow involves repetitive erosion of the saturated layer and the unsaturated soil because of the continuous progress of surface infiltration. This instantaneous phenomenon of infiltration and erosion is one difficulty of numerical modeling of embankment failure due to overtopping flow. Figure 2 shows the state of the experiments on embankment erosion from overtopping flow and confirm that the progress of the wetting-front and erosion processes occurred quasisimultaneously because of overtopping flow on the backside slope. The infiltration speed is different in each sediment case; it is directly affected by the hydraulic conductivity of surface soil. In the case of small sediments, the wetting-front is close to the surface of the embankment. The erosion occurred just after the decrease in resisting shear stress due to suction, which was caused by a change in the soil condition from unsaturated to saturated. As a result, the erosion rate decreased in the case of small sediments in comparison to the experiments of high seepage velocity conditions. In contrast, in the case of high seepage 
velocity, the erosion rate was shown to be highest under saturated conditions because the resisting shear stress from the suction disappeared immediately on the backside slope. This difference in erosion rate influenced by saturation of the embankment surface is important for an appropriate estimation of progressive erosion. Therefore, taking into account the seepage flow processes, such as the variation in resisting shear stress due to suction and the erosion rate for saturated surface soil and for unsaturated soil below the saturated layer, is important to simulate the erosion process from overtopping flow.

This study attempted to develop a new model for the surface erosion process-a repetition of the erosion of saturated and unsaturated soils and surface infiltration as shown in Fig.3. The overtopping flow forms a saturated layer on the embankment surfaces from its infiltration, and unsaturated soil exists below the saturated layer. The saturated layer is eroded first; unsaturated soil is eroded next, and then infiltration occurs. To simulate the simultaneous process of erosion and the infiltration cycle, two pick-up rate formulas were used in both saturated and unsaturated conditions as a new approach. Eq. (12) was used to estimate the erosion rate of unsaturated soil and for the erosion of the saturated soil under the condition $\tau_{\text {suc* }}=0$.

The remaining problem faced by this modeling method is to determine the thickness of the saturated layer. Generally, vertical resolution of a numerical mesh is not sufficient to simulate the thin saturated surface layer in seepage analysis. In an unsaturated condition on the surface mesh of an embankment, the thickness of the fully saturated layer was calculated by multiplying the hydraulic conductivity by the difference in the pressure head $(\Delta \psi)$ as follows:

$$
D_{s}=U_{s} \Delta t=-K_{z} \Delta \psi \Delta t
$$

where $U_{s}$ is the progress speed of the saturated layer, $K_{z}$ is the hydraulic conductivity in the vertical direction, and $\Delta t$ is the time step for the calculation of both seepage and erosion processes. The erosion of the saturated layer was calculated using the erosion rate formula for saturated conditions, the required time for one-step to erode the entire saturated layer was calculated using the following equation, and the remaining time in the one-step is used to erode the unsaturated soil:

$$
\begin{gathered}
\Delta t_{s}=D_{s} / E_{r s} \\
\Delta t_{u}=\Delta t-\Delta t_{s} \quad\left(\Delta t_{u} \geq 0\right) \\
E_{r} \Delta t=E_{r s} \Delta t_{s}+E_{r u} \Delta t_{u}
\end{gathered}
$$


where $E_{r s}$ and $E_{r u}$ are erosion rates calculated from pick-up volume on each cell for the saturated layer and the unsaturated soil, respectively, and $\Delta t_{s}$ and $\Delta t_{u}$ are variable time-steps for the erosion of the saturated layer and the unsaturated soil within the time of one-step $(\Delta t)$, respectively.

This modeling enables treatment of both saturated and unsaturated soil in a one-step erosion process, such as erosion of only the saturated layer or erosion of both saturated and unsaturated layers. In addition, if the simulated result of seepage analysis for saturation on the surface mesh shows full saturation, the erosion rate is calculated using only the formula for the saturated condition. As previously noted, the new model for the surface erosion process using the results of the seepage analysis - the effective saturation of the embankment surface - simulates erosion in both unsaturated and saturated soil conditions. The erosion rate could be calculated considering not only sediment size but also saturation and infiltration speed on an embankment surface.

\subsubsection{Calculation of deposition volume}

During the transport stage of sediment particles, some of the particles may continue moving, as described later, whereas some of them may be deposited onto the bed surface at a certain place. The amount of sediment deposition on the bed along the sediment transport trajectory is estimated using the probability density function for the step length:

$$
V_{d(n)}=V_{p} f_{s}\left(s_{(n)}\right) \Delta s
$$

where $V_{d(n)}$ is the deposition volume of the sediment after the $n$th step of movement, $f_{s}$ is the probability density function of the step length, and $s_{(n)}$ is the distance that a sediment particle moves from the pick-up point. The probability density function is written as follows (Nakagawa et al. 1982):

$$
f_{s}\left(s_{(n)}\right)=1 / \lambda \exp \left(-s_{(n)} / \lambda\right)
$$

where $\lambda$ is the average step-length of a sediment particle, which is estimated from the suggestion by Sekine and Kikkawa (1992) as follows:

$$
\lambda=\alpha_{2}\left(\frac{u_{*}}{w_{0}}\right)^{3 / 2}\left[1-\frac{\left(u_{*_{c}} / w_{0}\right)}{u_{*} / w_{0}}\right]
$$

where $\alpha_{2}$ is a constant $\left(=3.0 \times 10^{3}\right), u_{*_{c}}$ is critical the friction velocity, and $w_{0}$ is the settling velocity of the sediment estimated from the formula by Rubey (1933). The distance that a 
sediment particle moves is calculated from the local shear stress that exceeded the criteria for motion.

\subsubsection{Calculation of sediment trajectory}

After being picked up, sediment particles move near the bed and some may deposit somewhere on the bed. Sediment movement velocity and information on the trajectory of the movement of sediment particles are important when considering the effects of twodimensional geometry with respect to erosion and to investigate the location of deposition. The target of this study is to model the surface erosion; thus, the difference from this sediment movement process is not so effective in this simulation, and this part of the modelling considered the extensibility of the model for our future work. By omitting inter-particle collisions, the movement velocity $\mathbf{u}_{\text {sed }}$ of a sediment particle is calculated using its motion equation. Two unit vectors parallel to the local bed surface are defined as: $\mathbf{p}_{b 1}$ on the $x-Z$ plane and $\mathbf{p}_{b 2}$ on the $y-z$ plane. Then, the motion equation of a sediment particle in the $\mathbf{p}_{b j}$ $(j=1,2)$ direction is written as follows:

$$
m_{\text {sed }} \frac{D u_{\text {sed }(j)}}{D t}=D_{j}+W_{j}-F_{j} \quad(j=1,2)
$$

in which

$$
m_{\text {sed }}=\rho\left(\sigma / \rho+C_{m}\right) A_{3} d^{3}
$$

where $m_{\text {sed }}$ is the submerged weight of the sediment particle, $u_{\text {sed }(j)}$ is the component of sediment movement velocity in the $j$ direction, $D_{j}, W_{j}$, and $F_{j}$ are the components representing drag force on a particle, submerged weight of sediment particle, and friction force between sediment particle and the bed in the $j$ direction, respectively; and $C_{m}$ is the coefficient of added mass (=0.5). The magnitude of the drag force, particle submerged weight, and friction force for sediments are obtained as follows:

$$
\begin{gathered}
D=1 / 2 C_{D} \rho\left(u_{b(j)}-u_{\text {sed }(j)}\right)^{2} C_{E} A_{2} d^{2} \\
F=\mu_{k}\left(W \frac{\cos \theta_{b x} \cos \theta_{b y}}{\sin \theta_{p}}-k_{L} D\right) \\
W=(\sigma-\rho) g A_{3} d^{3}
\end{gathered}
$$

where $u_{b(j)}$ is the velocity of the component near the bed flow in the $j$ direction, $C_{D}$ is the drag coefficient (=0.4); $C_{E}$ is the coefficient accounting for the effective application area of 
the drag force ( $C_{E}=1.0$ is used for moving particles and $C_{E}=0.4$ is used for static particles); $\mu_{k}$ is the coefficient of kinetic friction of sediment particles (=0.35); $\theta_{b x}, \theta_{b x}$ are the angles of the local bed inclination in the $x$ and the $y$ direction, respectively; and $\theta_{p}$ is the angle between $\mathbf{p}_{b 1}$ and $\mathbf{p}_{b 2}$.

\subsubsection{Calculation of embankment shape}

Using the volumes of pick-up sediments and deposition sediments, which are calculated as previously described, the variation in the embankment shape is expressed as follows:

$$
\frac{\partial z_{b}}{\partial t}=\frac{A_{1} A_{2}}{A_{3}} \frac{\sum V_{d}-V_{p}}{S_{d}}
$$

where $z_{b}$ is the surface level of the embankment, $A_{1}$ is the shape coefficient of the sediment particle for $1 \mathrm{D}$ geometrical properties ( $A_{1}=1.0$, i.e., be always explicit), $\sum V_{d}$ is the total volume of deposited sediments in each computational cell at each time step, and $S_{d}$ is the projected area of the computational cell in which sediment is deposited.

\subsection{Calculation of mass sliding}

During the erosion process of the embankments due to overtopping flow, for an embankment consisting of cohesive sediment or fine non-cohesive sediment, the possibility exists that the shape of the backside slope becomes an overhang and a near-vertical slope due to the erosion of the toe of backside slope. Because the overhang condition and a near-vertical side slope are unstable, sediment sliding sometimes occurs locally as part of the embankment failure process. Therefore, some type of sliding process is required in a numerical model to simulate the entire embankment failure process.

Numerous studies that analyzed slope stability have been proposed and are available. Several previous studies introduced slope stability analysis in the calculation of embankment failure (e.g., Tingsanchali and Chinnarasri 2001, Wang et al. 2007). This study used the simplified Janbu method to search for the critical slip surface by calculating the safety factor. The sliding mass is divided into a number of vertical slices, and the static equilibrium conditions of each slice are considered as the sum of the vertical force equal to zero and the sum of the forces parallel to the slip surface equal to zero. The safety factor equation states the ratio between the resisting and the driving forces as follows:

$$
F_{s}=\sum_{i} R_{i} / \sum_{i} T_{i} \quad\left(i=1,2, \cdots, n_{s}\right)
$$




$$
\begin{gathered}
R_{i}=\frac{c^{\prime} l_{i} \cos \alpha_{s i}+\left(W_{i}-p_{w i} l_{i} \cos \alpha_{s i}\right) \tan \phi}{\cos ^{2} \alpha_{s i}\left(1+\tan \alpha_{s i} \tan \phi / F_{s}\right)} \\
T_{i}=W_{i} \tan \alpha_{s i}
\end{gathered}
$$

where $n_{s}$ is the total number of slices, $i$ is the slice number, $R_{i}$ is the shear strength in each slice, $T_{i}$ is the mobilized shear forces in each slice, $W_{i}$ is the weight of each slice, $l_{i}$ is the length of the base of each slice, $p_{w i}$ is the average pore-water pressure on the base of the slice, $\alpha_{s i}$ is the inclination of the bottom of each slice, and $c^{\prime}$ is the effective cohesion of the material of the embankment body. Equation (36) is derived without considering negative pore-water pressures that cause the resisting shear force in unsaturated soil. To introduce the effect of resisting shear stress from suction into the slope stability analysis, the shear strength $\left(R_{f}\right)$ is expressed as follows:

$$
R_{f}=c^{\prime}+\left(\sigma_{n}-p_{w}\right) \tan \phi+\tau_{\text {suc }}
$$

in which $\sigma_{n}$ is the total normal stress and $\tau_{\text {suc }}$ is resisting shear stress calculated using Eq. (15). Using equation Eq. (38) for shear strength, the slip surface safety factor can be defined as follows:

$$
F_{s}=\frac{\sum_{i=1}^{n_{s}}\left\{\left(c^{\prime} l_{i}+\left(N_{i}-p_{w i} l_{i}\right) \tan \phi+\tau_{\text {suc } i} l_{i}\right)\right\}}{\sum_{i=1}^{n} W_{i} \sin \alpha_{s i}}
$$

in which

$$
N_{i}=\frac{W_{i}-\frac{1}{F_{s}}\left(c^{\prime}+p_{w i} \tan \phi+\tau_{\text {suc } i}\right) l_{i} \sin \alpha_{s i}}{\cos \alpha_{s i}\left(1+\frac{\tan \alpha_{s i} \tan \phi}{F_{s}}\right)}
$$

The simulated results of seepage analysis are used in this slope stability analysis, indicating that the results of water content are used to calculate the weight of each slice; the pressure head results are used to calculate the value of average pore-water pressure on the base of slices; and the results of negative pore-water pressure are used as previously noted. In addition, the dynamic programming method, which has been developed as a numerical algorithm for the rapid optimization of sequential multistage decision problems, is used to determine the critical slip surface with the lowest safety factor and is mainly based on research by Yamagami and Ueta (1986). The algorithm combines Janbu's simplified method with dynamic programming based on the ideas of Baker (1980). 
Considering the process of the movement of sliding mass it is necessary to simulate the entire embankment failure process. Several studies did not consider this movement process after the calculation of the critical slip surface and treated it as the removal of sliding mass (Tingsanchali and Chinnarasri 2001, Wang et al. 2007). They assumed that the sliding soil mass is transported downstream completely and immediately. However, if the sliding mass is large, to some extent it influences flow near the area of deposition and the total time to embankment failure is influenced by the treatment of the soil mass after sliding. This study introduced a simple moving method for sliding mass movement. The sliding mass is transported downstream where the slope angle becomes smaller than the angle of repose, maintaining the volume and longitudinal length of the soil mass. After this movement in the soil mass, erosion of the soil mass sediments is calculated in the same way as the calculation of the pick-up sediments eroded from other embankment surfaces. A schematic diagram of this treatment of soil mass movement is shown in Fig. 4.

\section{Laboratory experiments of embankment erosion}

A series of flume experiments were carried out to investigate the erosion mechanism of a river embankment. In particular, discussions of the experiments focus on the influence of the differences in saturation of the embankment body for the erosion due to overtopping flow.

\subsection{Experimental setup and cases}

The experiments used a $5 \mathrm{~m}$ long, $30 \mathrm{~cm}$ wide, and $50 \mathrm{~cm}$ deep flume (Fig. 5). The flume slope was set to zero (horizontal). The details of the river embankment are shown in Fig. 6. Two types of embankment dams were used for the experiments. The embankment dam TypeA was made on the fixed bed surface, and Type-B was made on the erodible bed surface. The size of embankment Type-A is larger than Type-B. Three types of non-cohesive fine sediments (Fig. 7, Table 1) were used to construct each embankment, which were compacted to the same degree in $5 \mathrm{~cm}$ layers using a hammer with wooden boards to create the same pore volume and the same initial moisture content. Both side slopes were set to 1.0:2.0 (V: H), as indicated in Fig. 6. The side walls of the flume were made from clear acrylic board, making possible the observation of the erosion process from the side. A digital video camera was placed on the side of the flume to capture the temporal variation in the embankment shape resulting from erosion. These movies were later analyzed to determine the embankment surface profiles using the pasted scales on the side of the flume.

All experiments had a steady water discharge condition, as shown in Table 1 . The water was supplied from the upstream end of the flume. In Case-1, Case-2, Case-3, Case-4, Case-6, and Case-8, water was filled up to the level of the dam crown and overtopping 
occurred just after filling the reservoir without stopping the pump. Accordingly, the saturation condition of embankment body on the backside slope was equivalent to the initial condition, and this paper refers to these cases as "no infiltration cases". On the other hand, in Case-5, Case-7, and Case-9, the pump was stopped, and the flow discharge was adjusted to avoid overtopping after filling up the reservoir to the level of the dam crown. Infiltration occurred inside the embankment body by maintaining the water level up to the dam's crown height. After maintaining such high water level conditions, the soil condition became close to saturated in the body and backside slope, and a designated constant water discharge was supplied again to overtop the embankment. In the actual field, because river water may also infiltrate considerably the embankment before flow overtopping, we also carried out experiments under such conditions. The duration time of maintaining a high water level was different in each case because the infiltration speed differed for each sediment. The duration time of Case-5, Case-7, and Case-9 was set at 30 minutes, 90 minutes, and 180 minutes, respectively.

\subsection{Results of the laboratory experiment}

\subsubsection{Embankment erosion under different sediment conditions}

Figure 8 shows the erosion process; i.e., the variation in embankment shape over time for Case-4, Case-6, and Case-8. Each experiment was performed three times with identical pore volume and moisture content, and the embankment shapes in Fig. 8 were obtained from the average of each experimental result. These experimental results indicated that the sediment size condition has a significant effect on embankment erosion. The sediment size of sediment- 8 is smaller than that of sediment- 6 and sediment-7. However, these figures clearly show that the erosion rate of a non-cohesive embankment is lower in the case of sediment-8 than in sediment-6 and sediment-7. As sediment size becomes small, the erosion rate decreases.

Soil parameters for different types of sand used in these experiments were estimated by laboratory experiments conducted by Nakagawa et al. (2011). Table 2 lists the detailed values of the soil parameters for each sediment. Parameters related to the matric potential of soil $(\alpha, \eta)$ used in the soil moisture retention curve (Fig. 9) in the equation given by Van Genuchten (1980) were estimated using a non-linear regression analysis of soil-water retention data obtained by $\mathrm{pF}$ meter experiments under the wetting process. The relationship between the resisting shear stress due to suction ( $\tau_{\text {suc }}$ ) and pressure head $|\psi|$ is shown in Fig. 10 using the parameters in Table 2 in Eq. (15). The degree of resisting shear stress due to suction has a connection to sediment size, and the inter-particle force increases as sediment size becomes smaller. The low erosion rate in sediment-8 therefore results from an increase in 
resisting shear stress due to suction. The shear strength decreases when approaching saturated conditions-i.e., the matric suction is close to zero under saturated conditions. Therefore, when applying a sediment transport formula used in a calculation of riverbed variation for embankment erosion, adequately reproducing the erosion phenomena is difficult because of the lack of an effect of resisting shear stress with respect to suction under unsaturated soil in most sediment transport formulas. An inverse relationship generally exists in fine noncohesive sediment between sediment size and erosion rate versus sediment size and the volume of sediment transport calculated by the sediment transport formula of a riverbed.

\subsubsection{Influence of saturation on erosion process}

Figure 11 shows the progress of the wetting front in the embankment body due to the infiltration from the riverside slope in the case of sediment- 6 and sediment-8. The rates of progress of wetting fronts in sediment- 6 and sediment- 8 are significantly different. By comparing the experimental results obtained from using same sediment size and different saturation conditions before overtopping in the embankment body, the difference in the erosion rate can be confirmed. For each case of embankment Type-B, three types of noncohesive fine sediments and two types of saturation conditions were carried out, as shown in Table 1.

In order to investigate the influence of the infiltration effect on resisting shear stress due to suction, we compared the experimental results of the same time from the start of overtopping under different initial saturation conditions with the same sediments (Fig. 12). The results confirmed that a small difference in embankment shape existed between Case-4 and Case-5, which included relatively large sediment sizes and high infiltration rate conditions compared with other cases. For sediment-7 and sediment-8, the difference in shape occurred particularly in the lower part of the backside slope. The difference was greatest for sediment-8, which had the lowest infiltration rate condition. The low infiltration rate caused large differences in saturation in the embankment body for the different initial saturation cases. As a result, more time was required to make embankment surface condition saturated, and the erosion rate decreased compared to the other cases. The degrees of resisting shear stress due to suction are also different, depending on sediment size, and result in different erosion rates among the cases of different sediment sizes in a short time. However, it seems reasonable to conclude that the difference in erosion under the same sediment size conditions is influenced by the time required for the resisting shear stress to disappear from the surface infiltration progress. The difference in erosion rate was primarily caused by the difference in the saturation condition before overtopping in these experiments. The minimal difference in the erosion rate in the same sediment- 6 condition (Case- 4 and Case-5) resulted from the fact that the time required for the resisting shear stress to disappear from the embankment surface 
was almost the same because of the high infiltration rates and the easy-to-reach saturated condition on the surface. In other words, the erosion rate of the unsaturated condition under high infiltration is close to the erosion rate that is based on a saturated condition because the resisting shear stress from the suction disappeared immediately on the backside slope.

These experiments showed that the degree of resisting shear stress due to suction and the required time to change from an unsaturated soil condition to a saturated condition on the embankment surface (i.e., infiltration rate of the embankment surface) are important factors in the numerical modeling of the embankment erosion process, hence introducing the processes of seepage flow, variation in resisting shear stress due to suction, and an appropriate estimation of erosion rate for saturated surface soils and unsaturated soils into a numerical model are important in simulating the complicate erosion process on unsaturated soils.

\section{Numerical simulation}

\subsection{Computational conditions}

The meshes used for the calculation of surface flow and seepage belong to structured mesh, and the resolution of the computational mesh was set to $\Delta x=1.0 \mathrm{~cm}$ in the embankment body region and to $\Delta x=2.0 \mathrm{~cm}$ in other regions of the entire flume area; to $\Delta y=1.0 \mathrm{~cm}$ in a transverse direction for the calculation of flow; and to $\Delta \mathrm{x}=1.0 \mathrm{~cm}$ and $\Delta \mathrm{z}=0.5 \mathrm{~cm}$ for the calculation of seepage flow inside the embankment. Soil parameters for different sands used in these calculations were determined by laboratory experiments conducted by Nakagawa et al. (2011). Table 2 lists the detailed values of the soil parameters for each sediment.

\subsection{Simulation results}

A numerical simulation of laboratory experiments on embankment erosion was carried out using the developed numerical model. Figure 13 shows a comparison of the simulated and experimental results of Case-1, Case-2, and Case-3. The temporal progresses of erosion were well reproduced by the present numerical model. In particular, the simulated results of the sediment-7 case showed quite good agreement with the experimental results. In the case of small sediments (sediment-8), the erosion rate was less in comparison with large sediment conditions (i.e., sediment-6 and sediment-7) because of the introduction of suction effects. The total time of dam failure become longer as was seen in the experiment results. Reproducing such a lag time for erosion in small sediments using an original sediment transport formula used in riverbeds without modification or adjustment of the coefficients related to erodibility depending on embankment materials is difficult. Therefore, it can be said that the improvement in numerical reproducibility of the temporal change in embankment 
shape is an important point in this study and a major advancement in modeling the surface erosion of unsaturated embankments. However, the embankment shapes during the erosion process did not coincide completely with the experiments. For example, the erosion did not occur near the top of the slope of the waterside in the earlier stage of erosion for sediment-8. This means that some problems remain in the estimation of erosion rate or in the calculation of flow, and further investigations are needed to improve these results.

Figure 14 shows the comparison of the simulated results obtained considering the suction effect and the simulated results without considering the suction effect. Because of the relatively high infiltration rate condition, the difference in simulated results for sediment-7 compared with sediment-8 is not significant. On the contrary, for sediment-8, the conditions of low infiltration and high resisting shear stress significantly influenced the erosion rate in these numerical simulations. Secondly, we also conducted a sensitivity analysis to check the influence of the hydraulic conductivity of the embankment dam soil on erosion. The simulated results at 40 and 100 second from the start of overtopping in Case-3 under different permeabilities, $K_{s}=7.8 \times 10^{-6}, 1.56 \times 10^{-5}$ and $3.12 \times 10^{-5}$ (half of the measured value, the same as the measured value, and twice the measured value, respectively) are shown in Fig. 15. The difference in hydraulic conductivity significantly influenced the erosion rate in the proposed numerical model. The difference in permeability leads to a longer or shorter period of change from an unsaturated condition to a saturated condition on the surface; hence, the duration for a high resisting shear stress condition is strongly affected by the surface permeability condition.

Furthermore, we conducted a grid sensitivity calculation to check the influence of the grid size sensitivity on the erosion rate of this new modeling. The target was the vertical resolution of the numerical mesh in seepage calculations. The horizontal meshes were thus set to the same conditions. The resolution of a numerical mesh is not generally sufficient to simulate the actual thin saturated surface layer during the simultaneous occurrences of erosion and infiltration due to overtopping flow, as stated above. Accordingly, it is desirable that the simplification is introduced in the erosion modeling of unsaturated soils considering the infiltration effects without using finer mesh. The erosion modeling of this study used the information regarding saturation on surface meshes for to evaluate resisting shear stress due to suction on the unsaturated soil erosion. So different mesh size affects the time variation of surface saturation and erosion rate, especially the erosion parts of unsaturated soils, namely, the second term on the right side of Eq. (25). Figure 16 shows the comparison of experimental results and the results of two cases of numerical simulations under different vertical mesh sizes; $\Delta \mathrm{z}=0.5 \mathrm{~cm}$ and $\Delta \mathrm{z}=1.0 \mathrm{~cm}$, at $20,40,60$ and 80 second. The simulation with the coarser mesh did not agree well with experimental results as did the finer mesh results. As can be seen from Fig. 16, the erosion rate on the backside slope was less than that of the finer mesh 
results due to the difference in time necessary to change from unsaturated to saturated conditions on the surface mesh. The time lag of change extends the low erosion time in coarse mesh simulation. The fine mesh can change to saturated conditions earlier on the surface because of the small control volumes. The determination of suitable mesh size for this erosion modeling remains a matter for further discussion. However, it was at least confirmed that the experimental results of embankment erosion using non-cohesive homogeneous embankments with three different sediment materials were well reproduced by the numerical simulation, which introduced the new erosion rate modeling that considers the infiltration effects of erosion of unsaturated soils under fine mesh condition.

\section{Conclusion}

The erosion process of an embankment made from a non-cohesive fine sediment was investigated through laboratory experiments, and a numerical model of embankment failure due to overtopping flow was developed.

The experimental results for the embankment made by non-cohesive fine sediments showed that the erosion rate in small sediment is lower compared to large sediment. In the embankment of small sediment, resisting shear stress due to suction is responsible for the lower erosion rate. We observed that the erosion of unsaturated embankment was highly influenced by the suction in unsaturated soil because the matric suction increases the shear strength. In addition, the conditions of saturation and the infiltration rate in the embankment also cause a difference in the erosion rate of the unsaturated embankment. Therefore, the resisting shear stress due to suction and infiltration rate from overtopping flow plays a vital role in the erosion of an embankment surface, and they are important factors in the numerical modeling of the erosion process for an embankment.

An embankment erosion model was developed using combined depth-averaged flow, seepage flow, a sediment transport model based on a non-equilibrium model, and a slope stability model. In this study, a new expression for resisting shear stress due to suction was derived in a pick-up formula to compute the erosion of an unsaturated river embankment by overtopping flow. We introduced an improved pick-up formula based on both saturated and unsaturated conditions to simulate the erosion process of the embankment surface that occurs simultaneously with infiltration. The proposed model was tested for embankment erosion with different sediment sizes. Overall, the numerical model reproduced well the processes of embankment surface erosion due to overtopping flow. In a condition of small sediments, the significant shear strength and the low infiltration rate cause a lag in erosion and a delay in the failure time, and the proposed model was able to reproduce these phenomena. A numerical model that can reproduce the temporal change of an embankment shape during the erosion 
process due to overtopping flow is important and useful to consider hazard assessment and a countermeasure for embankment failure and embankment design, and this study engaged in the improvement of surface erosion treatment considering the infiltration effect of developing such a numerical model.

\section{Acknowledgments}

This work was supported by Grant-in-Aid for Scientific Research (B) (No.22360197) from the Ministry of Education, Culture, Sports, Science and Technology (MEXT), Japan; and the JSPS AA Science Platform Program (Coordinator: Dr. Hajime Nakagawa). It also received support from the Kyoto University Global COE Program (GCOE-ARS).

\section{Notations}

$A_{1}, A_{2}, A_{3}=$ shape coefficients of sediment particles for 1D, 2D, and 3D geometrical properties (-)

$c^{\prime}=$ effective cohesion of the material of embankment body $\left(\mathrm{Nm}^{-2}\right)$

$C$ = specific moisture capacity (-)

$C_{E}=$ coefficient accounting for the effective application area of the drag force (-)

$C_{D}=$ drag coefficient (-)

$C_{m}=$ coefficient of added mass (-)

$D_{s}=$ depth of fully saturated layer on the surface (m)

$d=$ diameter of sediment particles (m)

$d_{m}=$ mean diameter of sediment particles $(\mathrm{m})$

$E_{r}, E_{r s}, E_{r u}=$ erosion rate for total, saturated, and unsaturated soils $(\mathrm{m} / \mathrm{s})$

$f=$ friction coefficient (-)

$F$ = friction force $(\mathrm{N})$

$F_{s}=$ safety factor for slide event (-)

$g=$ acceleration of gravity $\left(\mathrm{m} / \mathrm{s}^{2}\right)$

$G_{*}=$ coefficient accounting for direction deviation between near bed velocity and sediment movement direction (-)

$h=$ flow depth $(\mathrm{m})$

$H$ = water level (m)

$k_{L}=$ ratio of lift force to drag force (-)

$K, K_{s}=$ unsaturated and saturated hydraulic conductivity $(\mathrm{m} / \mathrm{s})$ 
$K_{x}, K_{z}=$ hydraulic conductivity in the $x$ and $z$ directions $(\mathrm{m} / \mathrm{s})$

$l=$ length of the base of a vertical slice in slope stability analysis (m)

$m_{\text {sed }}=$ submerged weight of sediment particle $(\mathrm{kg})$

$n=$ Manning coefficient $\left(\mathrm{s} \mathrm{m}^{-1 / 3}\right)$

$n_{s}=$ total number of vertical slices in slope stability analysis (-)

$p_{a}, p_{w}=$ pore-air and pore-air pressure $\left(\mathrm{Nm}^{-2}\right)$

$p_{s}=$ pick-up rate $(1 / \mathrm{s})$

$R_{T}=$ drag force $(\mathrm{N})$

$s, \Delta s=$ distance that sediment particle moves from pick-up point and its one-step movement

(m)

$S_{e}=$ effective saturation (-)

$S_{d}=$ projected area of computational mesh $\left(\mathrm{m}^{2}\right)$

$S_{p}=$ projected area of computational mesh onto the horizontal plane $\left(\mathrm{m}^{2}\right)$

$t=$ time $(\mathrm{s})$

$u=$ depth-averaged flow velocity in the $x$ direction $(\mathrm{m} / \mathrm{s})$

$u_{b}=$ flow velocity acting on a sediment particle $(\mathrm{m} / \mathrm{s})$

$u_{\text {sed }}=$ movement velocity of a sediment particle $(\mathrm{m} / \mathrm{s})$

$u_{*}=$ friction velocity $(\mathrm{m} / \mathrm{s})$

$U_{s}=$ progress speed of saturated layer $(\mathrm{m} / \mathrm{s})$

$v=$ depth-averaged flow velocity in the $y$ direction $(\mathrm{m} / \mathrm{s})$

$V_{d}=$ deposition volume of sediment per unit time $\left(\mathrm{m}^{3} / \mathrm{s}\right)$

$V_{p}=$ volume of sediment pick-up per unit time $\left(\mathrm{m}^{3} / \mathrm{s}\right)$

$W$ = submerged weight of sediment particle $(\mathrm{N})$

$w_{0}=$ setting velocity of a sediment particle $(\mathrm{m} / \mathrm{s})$

$x, y, z=$ space coordinates $(\mathrm{m})$

$\alpha, \eta=$ parameters related to matric potential of the sediment (-)

$\alpha_{d}=$ angle between the maximum local bed slope and sediment movement direction (rad)

$\varepsilon=$ eddy viscosity $\left(\mathrm{m}^{2} / \mathrm{s}\right)$

$\phi=$ effective angle of internal friction (rad)

$\phi_{b}=$ coefficient accounting for local bed slope and direction deviation between maximum local bed slope and sediment movement direction (-)

$\kappa=$ von Karman constant (-) 
$\lambda=$ average step length of a sediment particle (-)

$\theta_{b}=$ local bed slope (rad)

$\theta_{w}=$ volumetric water content of the soil (-)

$\theta_{r}, \theta_{s}=$ saturated and residual moisture content of the soils (-)

$\mu_{k}=$ coefficient of kinetic friction (-)

$\mu_{s}=$ static friction factor $(-)$

$\rho=$ density of water $\left(\mathrm{kg} / \mathrm{m}^{3}\right)$

$\sigma=$ density of sediment $\left(\mathrm{kg} / \mathrm{m}^{3}\right)$

$\sigma_{n}=$ total normal stress on the base of a vertical slice $\left(\mathrm{Nm}^{-2}\right)$

$\tau_{b x}, \tau_{b y}=$ bottom shear stresses in the $x$ and $y$ directions $\left(\mathrm{Nm}^{-2}\right)$

$\tau_{\text {suc }}=$ resisting shear stress due to suction $\left(\mathrm{Nm}^{-2}\right)$

$\tau_{x x}, \tau_{y y}, \tau_{x y}=$ shear forces due to turbulence $\left(\mathrm{Nm}^{-2}\right)$

$\tau_{*}, \tau_{*_{c}}=$ dimensionless shear stress and critical shear stress for sediments (-)

$\psi=$ water pressure head $(\mathrm{m})$

$\psi_{b}=$ angle between the near bed velocity and the sediment movement direction (rad)

$\Delta t=$ one time step for erosion and flow calculation (s)

$\Delta t_{s}, \Delta t_{u}=$ time step for erosion of saturated and unsaturated soil (s)

\section{References}

Baker, R. (1980). Determination of the critical slip surface in slope stability computations. International Journal for Numerical and Analytical Methods in Geomechanics, 4, 333359.

Chinnarasri, C., Tingsanchali, T., Weesakul, S., Wongwises, S. (2003). Flow patterns and damage of dike overtopping. International Journal of Sediment Research, 18(4), 301309.

Egiazaroff, I. V. (1965). Calculation of nonuniform sediment concentrations. Proceedings of ASCE, 91(4), 225-247.

Faeh, R. (2007). Numerical modeling of breach erosion of river embankments. Journal of Hydraulic Engineering, ASCE, 133(9), 1000-1009.

Gotoh, H., Hyashi, M., Oda, K., Sakai, T. (2002). Gridless analysis of slope failure of embankment by overflow. Annual Journal of Hydraulic Engineering, JSCE, 46, 439444. 
Gotoh, H., Ikari, H., Tanioka, H., Yamamoto, K. (2008). Numerical simulation of riverembankment erosion due to overflow by particle method. Annual Journal of Hydraulic Engineering, JSCE, 52, 979-984.

Iwagaki, Y. (1956). (I) Hydrodynamical study on critical tractive force. Journal of JSCE. 41, $1-21$.

Nagata, N., Hosoda, T., Nakato, T., Muramoto, Y. (2005). Three-dimensional numerical model for flow and bed deformation around river hydraulic structures. Journal of Hydraulic Engineering, ASCE, 131(12), 1074-1087.

Nakagawa, H., Utsumi, T., Kawaike, K., Baba, Y., Zhang, H. (2011). Erosion of unsaturated river embankment due to overtopping water. Annual Journal of Hydraulic Engineering, JSCE, 55, S K-1-K4.

Nakagawa, H., Tsujimoto, T., Murakami, S. (1985). Non-equilibrium bed load transport process on a slide slope. Annual Journal of Hydraulic Engineering, JSCE, 29, 561-566.

Nakagawa, H., Tsujimoto, T., Nakano, S. (1982). Characteristics of sediment motion for respective grain sizes of sand mixtures. Bull. Disaster Prevention Research Institute, Kyoto University, 32(1), No.286.

Patankar, S. V. (1980). Numerical heat transfer and fluid flow. Hemisphere, Washington DC, 197.

Powledge, G.R., Ralston, D.C., Miller, P., Chen, Y.H., Clopper, P.E., Temple, D.M. (1989).

Mechanics of overflow erosion on embankments. II: Hydraulic and design considerations. Journal of Hydraulic Engineering, 115(8), 1056-1075.

Pickert, G., Weitbrecht, V., Bieberstein, A. (2011). Breaching of overtopped river embankments controlled by apparent cohesion. Journal of Hydraulic Research, 49(2), 143-156.

Rubey, W. W. (1933). Settling velocities of gravel, sand and silt particles. American Journal of Science, 25, 325-338.

Sekine, M., Kikkawa, H. (1992). Mechanics of saltating grains. II. Journal of Hydraulic Engineering, ASCE, 118(4), 536-558.

Tingsanchali, T., Chinnarasri C. (2001). Numerical modeling of dam failure due to overtopping. Hydrological Sciences-Journal-des Sciences Hydrologiques, 46(1), 113130.

Van Genuchten, M.T. (1980). A closed-form equation for predicting the hydraulic conductivity of unsaturated soils. Soil Science Society of American Journal, 44, 892-898.

Vanapalli, S.K., Fredlund, D. G., Pufahl, D. E., Clifton, A. W. (1996). Model for the prediction of shear strength with respect to soil suction. Canadian Geotechnical Journal, 33(3), 379-392. 
Wang, Z., Bowles, D., S. (2007). A numerical method for simulating one-dimensional headcut migration and overtopping breaching in cohesive and zoned embankments.

Water Resources Research, 43, W05411, 1-17.

Yamagami, T., Ueta, Y. (1986). Noncircular slip surface analysis of the stability of slopes: An application of dynamic programming to the Janbu method. Journal of Japan Landslide Society, 22(4), 8-16. 
Table 1. Experimental cases.

\begin{tabular}{|c|c|c|c|c|c|c|c|}
\hline \# & $\begin{array}{l}\text { Dam } \\
\text { Type }\end{array}$ & $\begin{array}{c}\text { Supply } \\
\text { discharge } \\
\left(\mathrm{cm}^{3} / \mathrm{s}\right)\end{array}$ & $\begin{array}{l}\text { Sediment } \\
\text { type }\end{array}$ & $\begin{array}{c}d_{m} \\
(\mathrm{~mm}) \\
\end{array}$ & $\begin{array}{l}\text { Infiltration before } \\
\text { flow overtopping }\end{array}$ & $\begin{array}{c}\text { Initial moisture } \\
\text { content of dam } \\
(\%)\end{array}$ & $\begin{array}{c}\text { Porosity of } \\
\text { dam body }\end{array}$ \\
\hline 1 & A & \multirow{3}{*}{7840.0} & No.6 & 0.334 & No & 13.0 & 0.51 \\
\hline 2 & A & & No.7 & 0.174 & No & 11.5 & 0.51 \\
\hline 3 & A & & No.8 & 0.100 & No & 12.0 & 0.55 \\
\hline 4 & B & \multirow{6}{*}{1172.0} & \multirow{2}{*}{ No.6 } & \multirow{2}{*}{0.334} & No & 3.89 & \multirow{2}{*}{0.53} \\
\hline 5 & B & & & & Yes & (5.86) & \\
\hline 6 & B & & \multirow{2}{*}{ No.7 } & \multirow{2}{*}{0.174} & No & 6.79 & \multirow{2}{*}{0.55} \\
\hline 7 & B & & & & Yes & (9.53) & \\
\hline 8 & B & & \multirow{2}{*}{ No.8 } & \multirow{2}{*}{0.100} & No & 4.59 & \multirow{2}{*}{0.58} \\
\hline 9 & B & & & & Yes & (5.71) & \\
\hline
\end{tabular}

* The values of initial moisture content between the brackets are the values before starting the pump to maintain the water level up to the dam height before overtopping.

Table 2. Parameters of different sediments.

\begin{tabular}{|c|c|c|c|}
\hline Parameters & No. 6 & No. 7 & No. 8 \\
\hline$\theta_{s}$ & 0.319 & 0.351 & 0.40 \\
\hline$\theta_{r}$ & 0.061 & 0.095 & 0.117 \\
\hline$\alpha$ & 3.837 & 2.552 & 1.107 \\
\hline$\eta$ & 3.852 & 4.148 & 2.254 \\
\hline$K_{s}(\mathrm{~m} / \mathrm{sec})$. & $2.15 \times 10^{-4}$ & $8.75 \times 10^{-5}$ & $1.56 \times 10^{-5}$ \\
\hline
\end{tabular}


Figure 1 Conceptual diagram of interaction among the modules: water flow module to morphology module (a) and morphology module to water flow module (b)

Figure 2 State of erosion and infiltration due to overtopping flow on the backside slope of an embankment

Figure 3 Schematic diagram of the erosion and infiltration process

Figure 4 Schematic diagram of sliding soil mass movement

Figure 5 Experimental flume

Figure 6 Details of embankment dam types

Figure 7 Particle size distributions of sediments

Figure 8 Experimental results of embankment shape, embankment dam Type-B: (a) Case-4,

(b) Case-6, and (c) Case-8

Figure 9 Soil-water characteristics curves

Figure 10 Relationship between resisting shear stress and matric suction

Figure 11 Progress of wetting fronts for sediment- 6 and sediment-8: Case- 5 (a) and Case-9 (b)

Figure 12 Comparison of experimental results obtained using different initial saturation conditions: Case-4 vs. Case-5 (a), Case-6 vs. Case-7 (b), and Case-8 vs. Case-9 (c)

Figure 13 Simulated and experimental results of dam shape, embankment dam Type-A (sim: simulation; exp: experiments): (a) Case-1, (b) Case-2, and (c) Case-3 
Figure 14 Comparison of simulated results obtained considering resisting shear stress due to suction effect and without considering resisting shear stress due to suction, embankment dam Type-A (non-suc: non-suction): (a) Case-2 and (b) Case-3

Figure 15 Simulated results for different hydraulic conductivity coefficients in Case-3, embankment dam Type-A $\left(\mathrm{K} 1 ; \mathrm{K}_{\mathrm{s}}=7.8 \times 10^{-6}, \mathrm{~K} 2 ; \mathrm{K}_{\mathrm{s}}=1.56 \times 10^{-5}, \mathrm{~K} 3 ; \mathrm{K}_{\mathrm{s}}=3.12 \times 10^{-5}\right)$

Figure 16 Simulated results for different mesh conditions in Case-2, embankment dam TypeA 


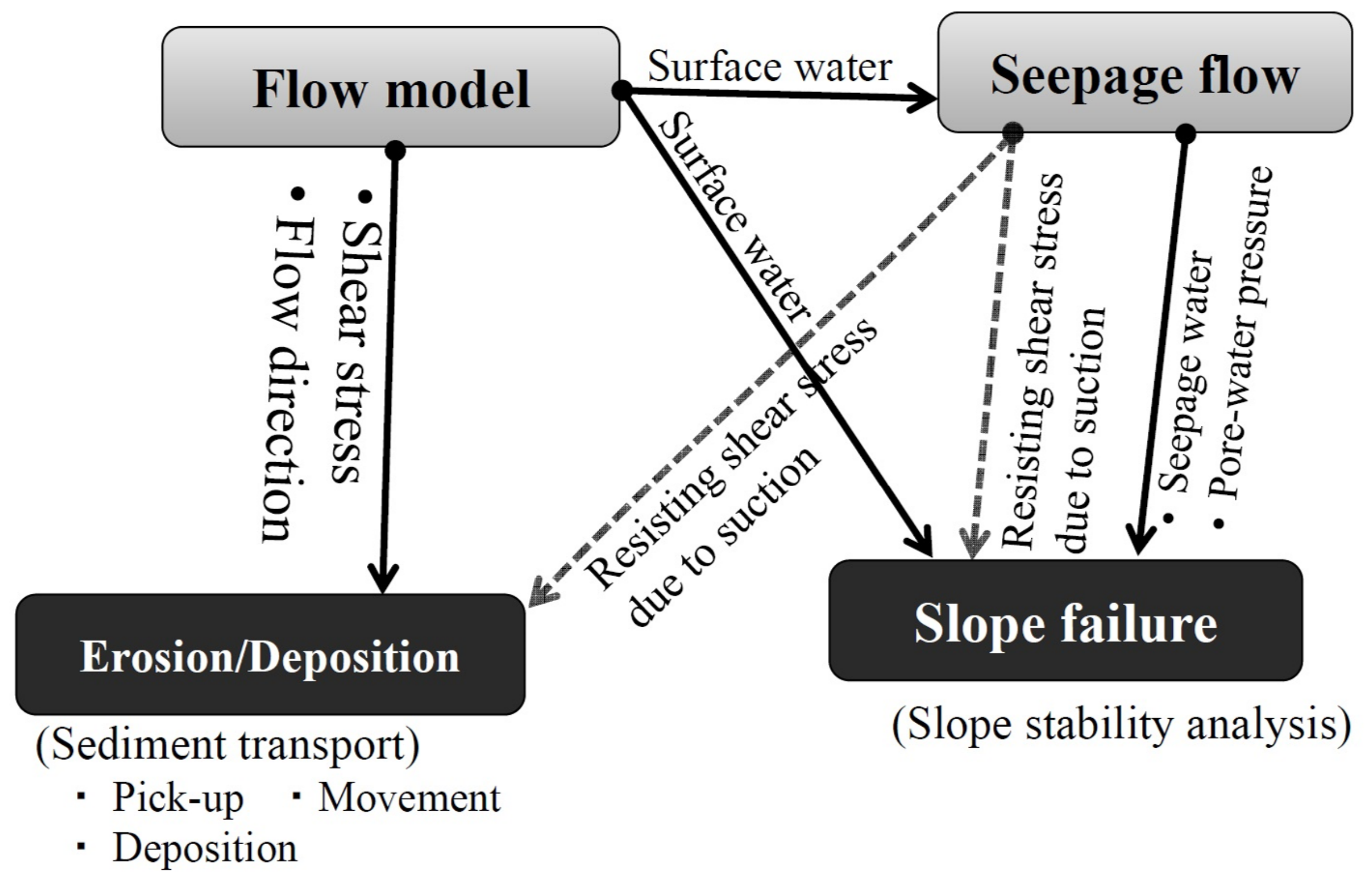

Figure 1 (a) 


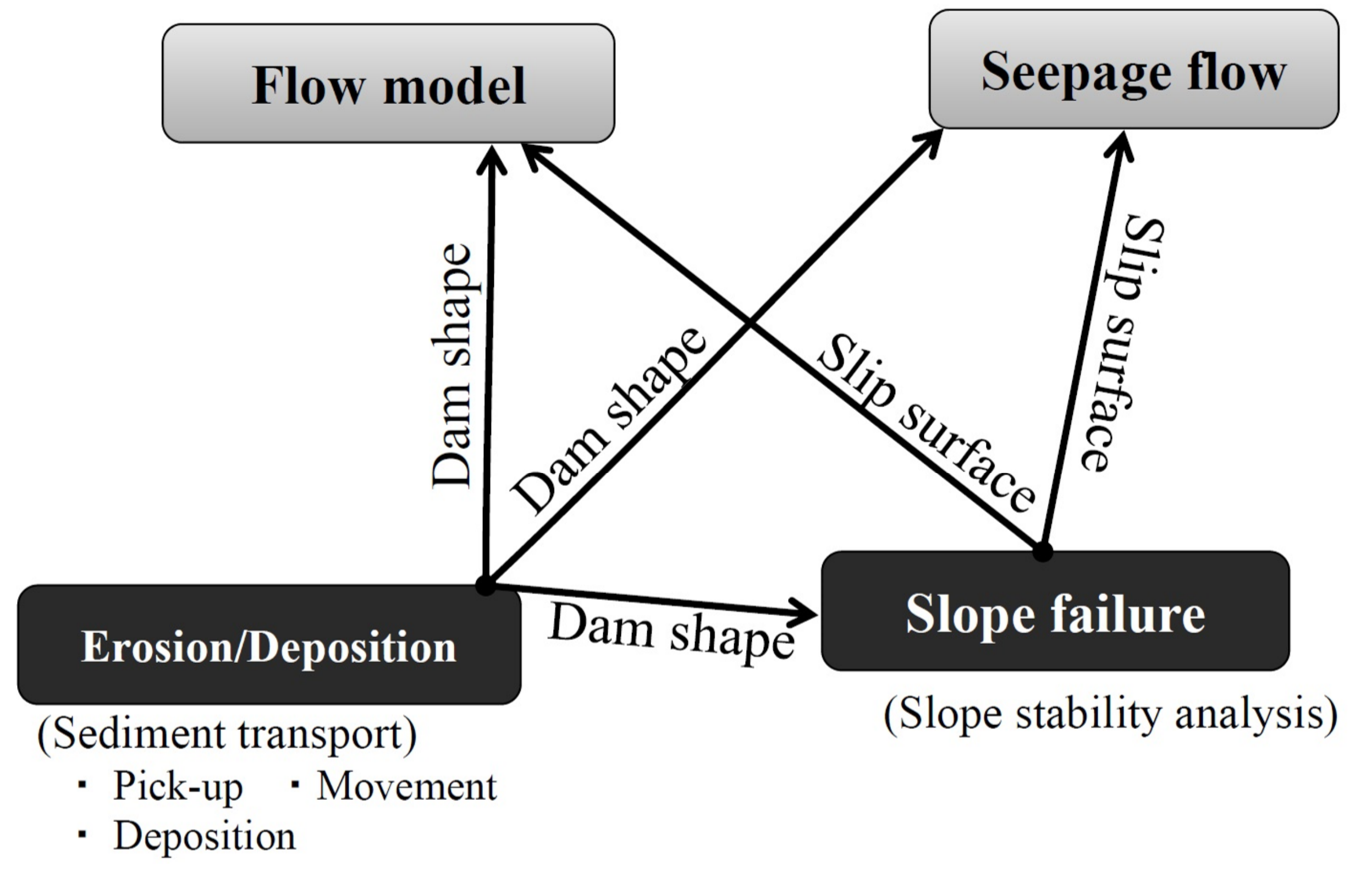

Figure 1(b) 

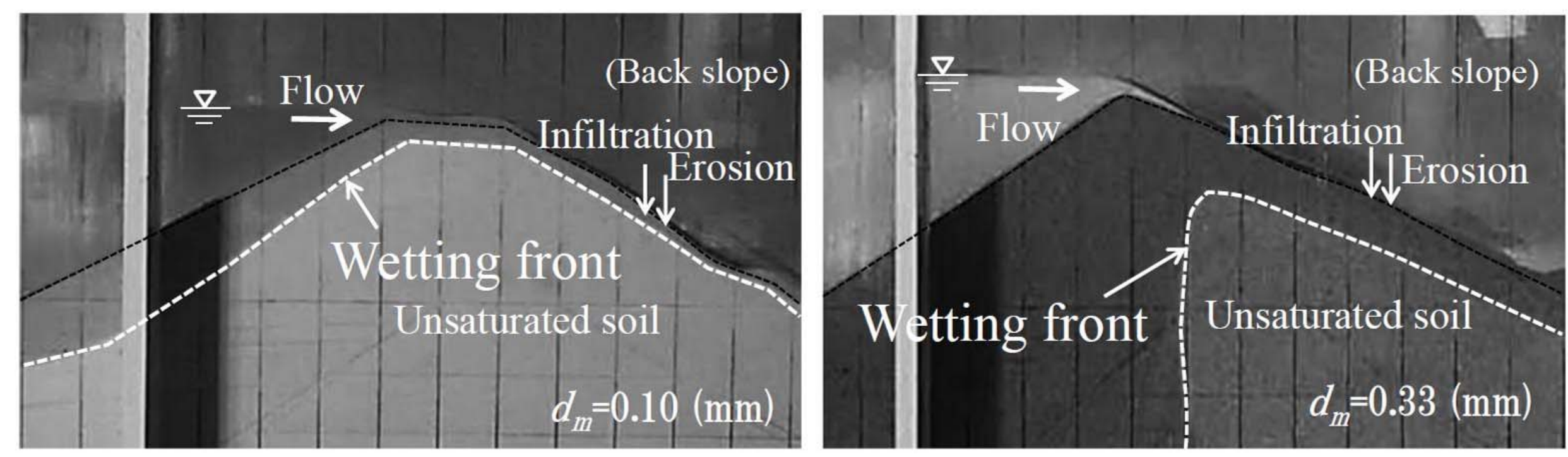

Figure 2 


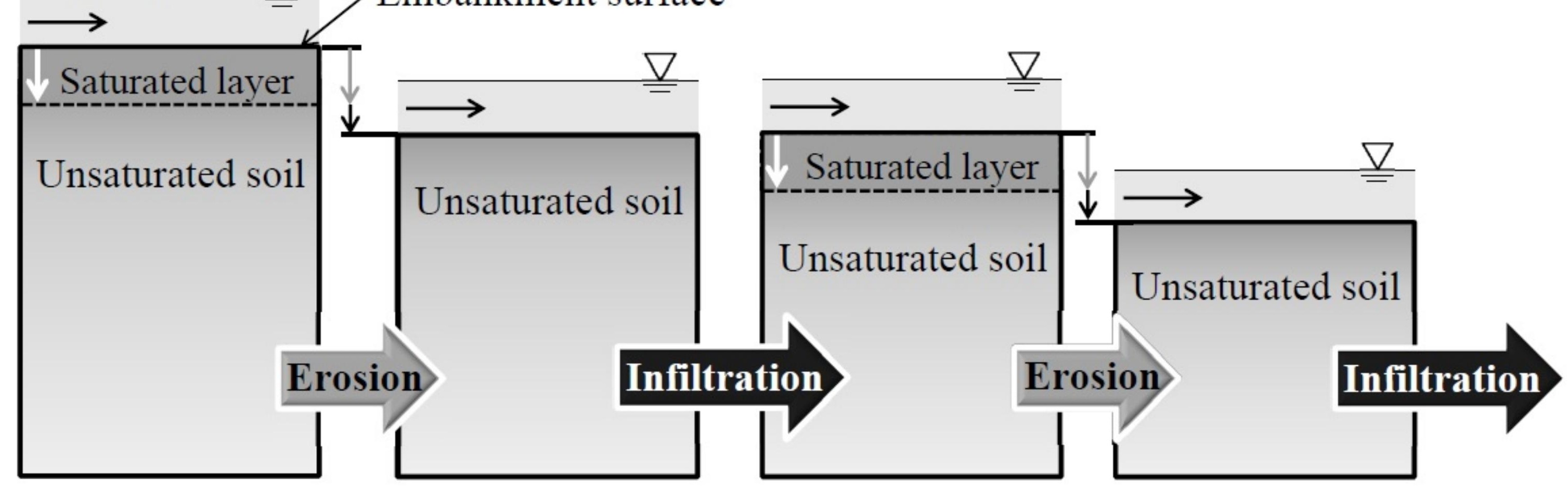




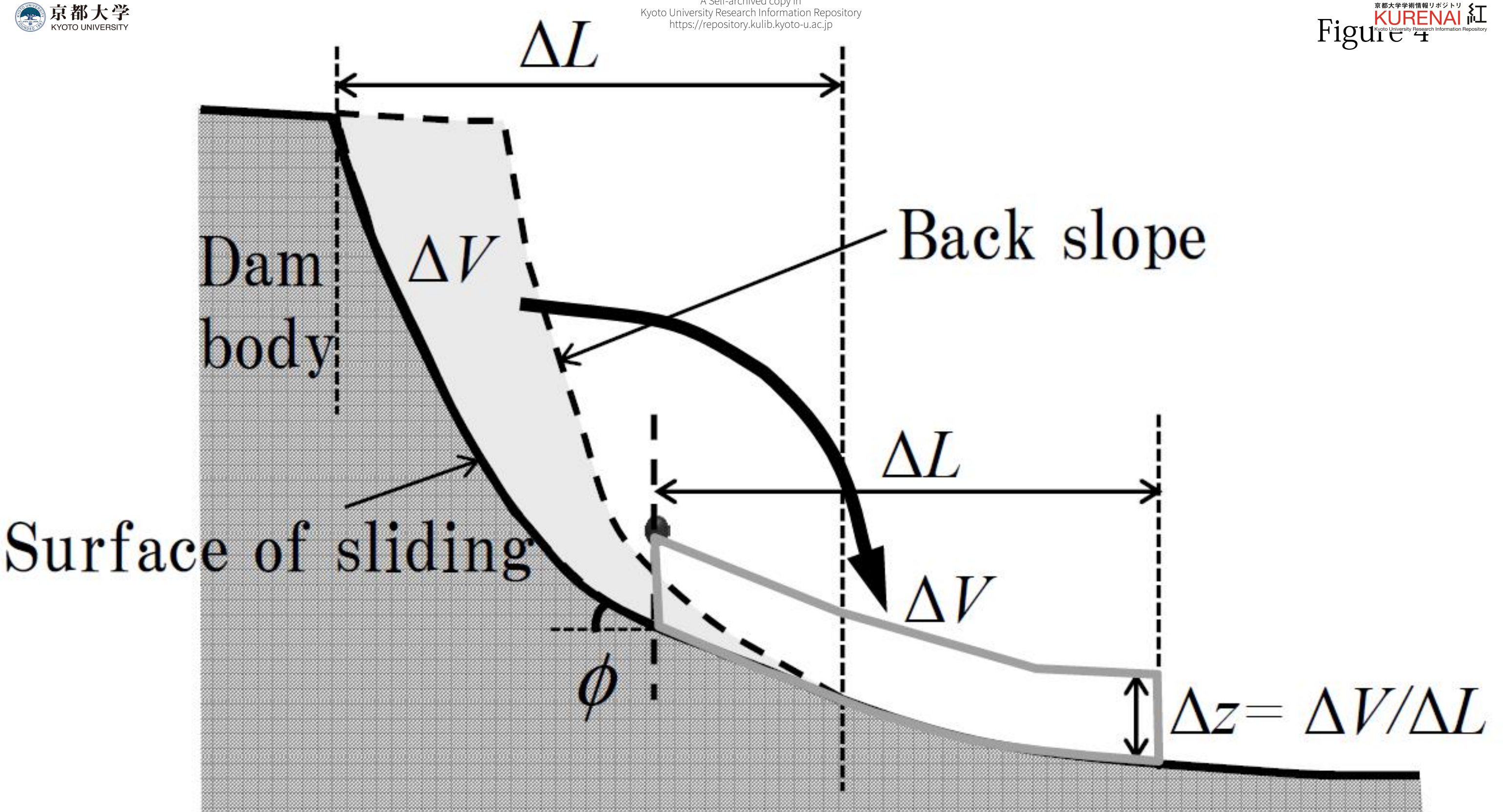




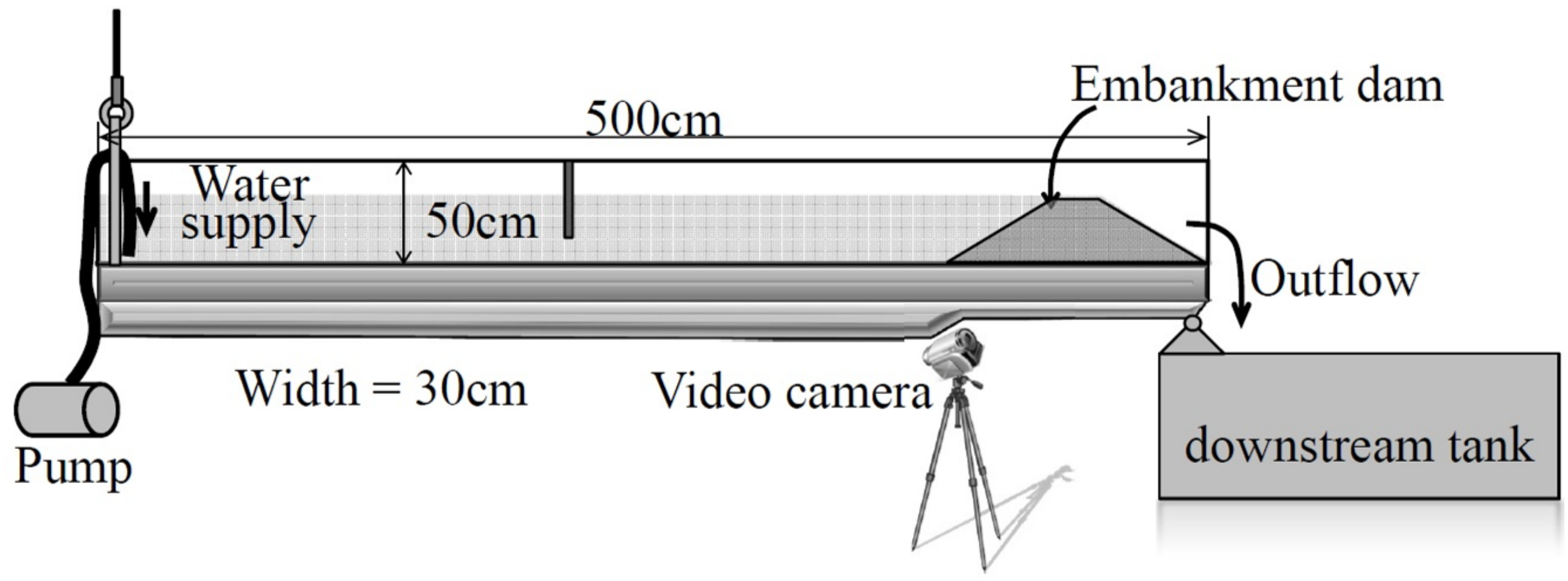

Figure 5 
- Type-A

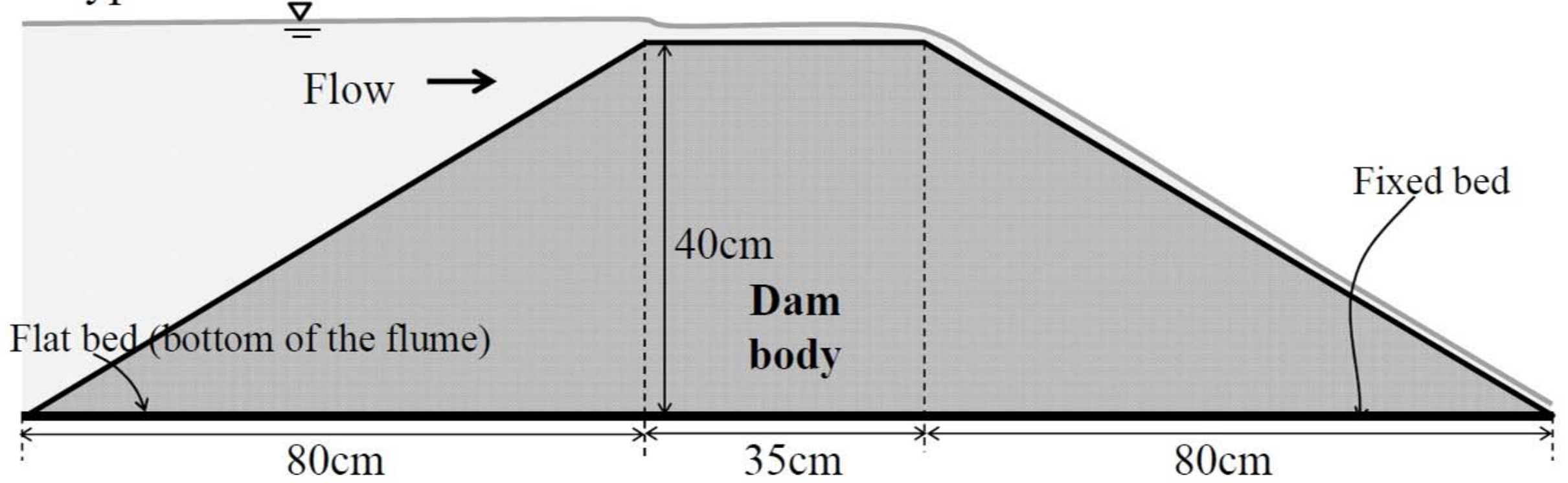

- Type-B

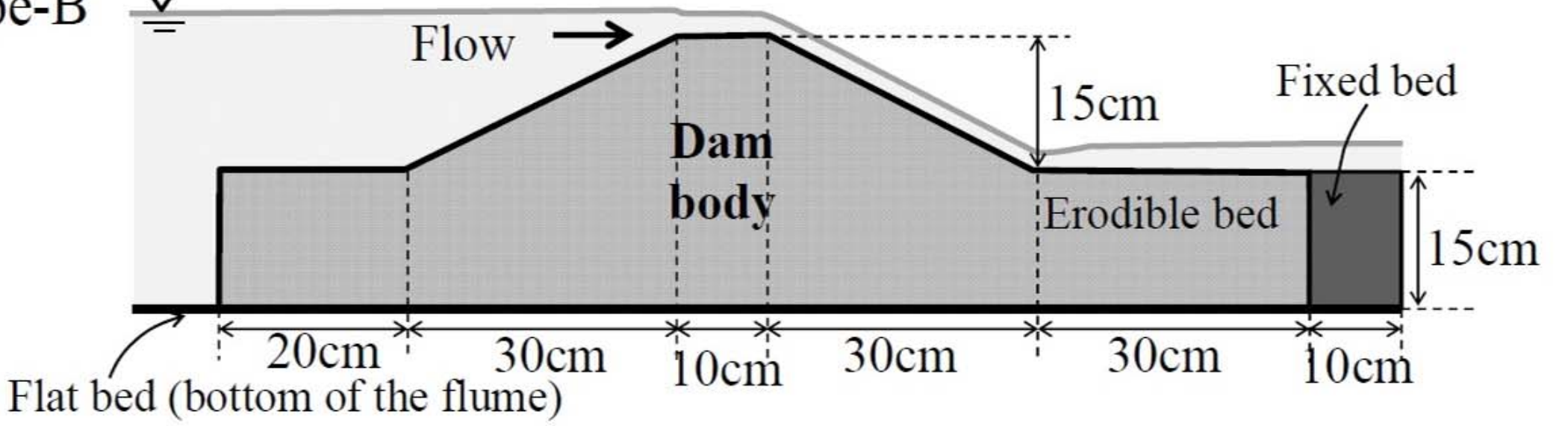




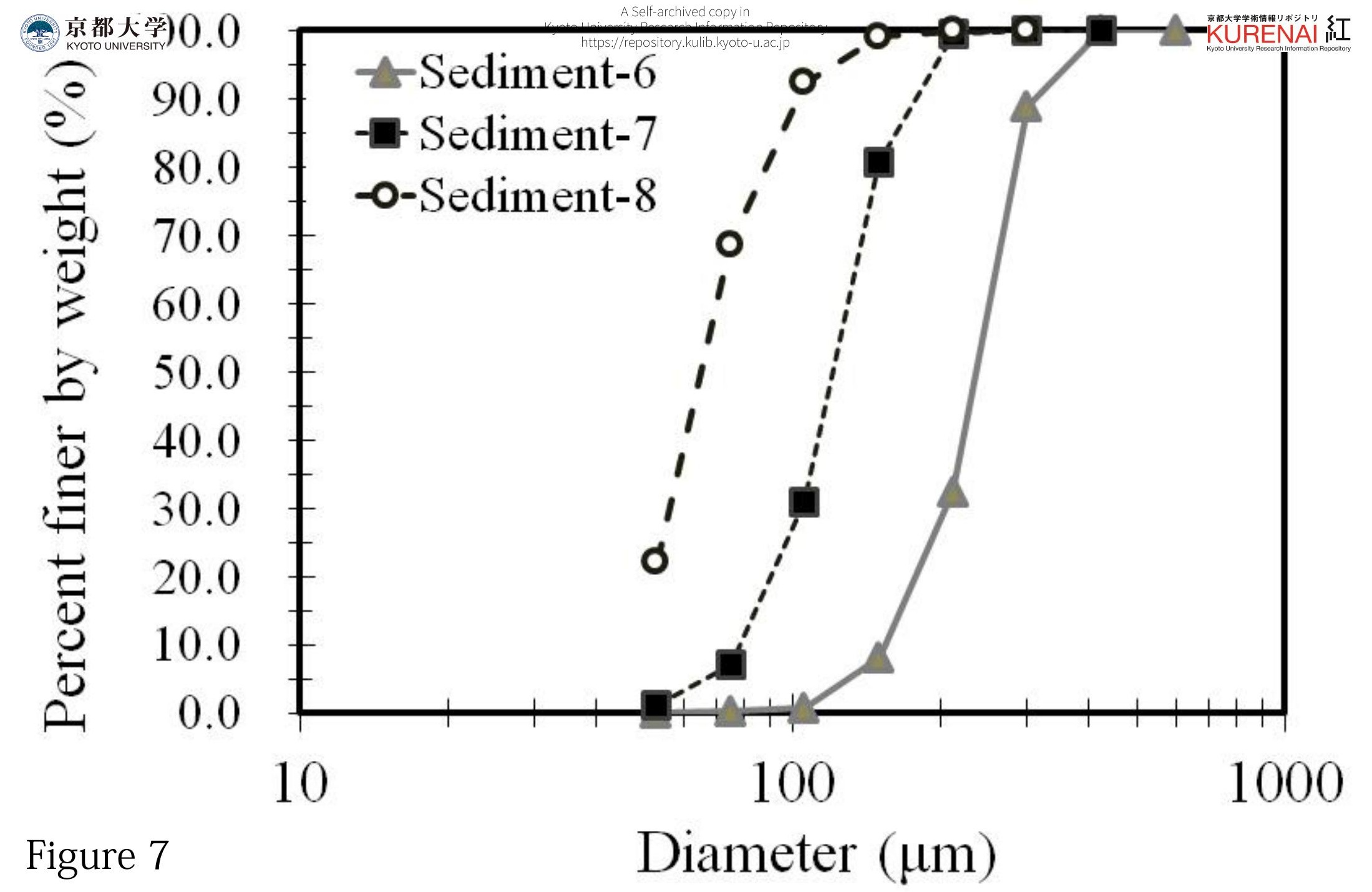


A Self-archived copy in

京都大学 KYOTO UNIVERS

$$
\text { Y }
$$

Kyoto httpsitory https:1/fepository.kulib.kyoto-u.acipns

$\rightarrow 50$ s $120 \mathrm{~s}$

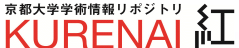
Kyoto University Research Information Repository $60 \mathrm{~s}$
$-. .70 \mathrm{~s}$

Figure 8 legend 


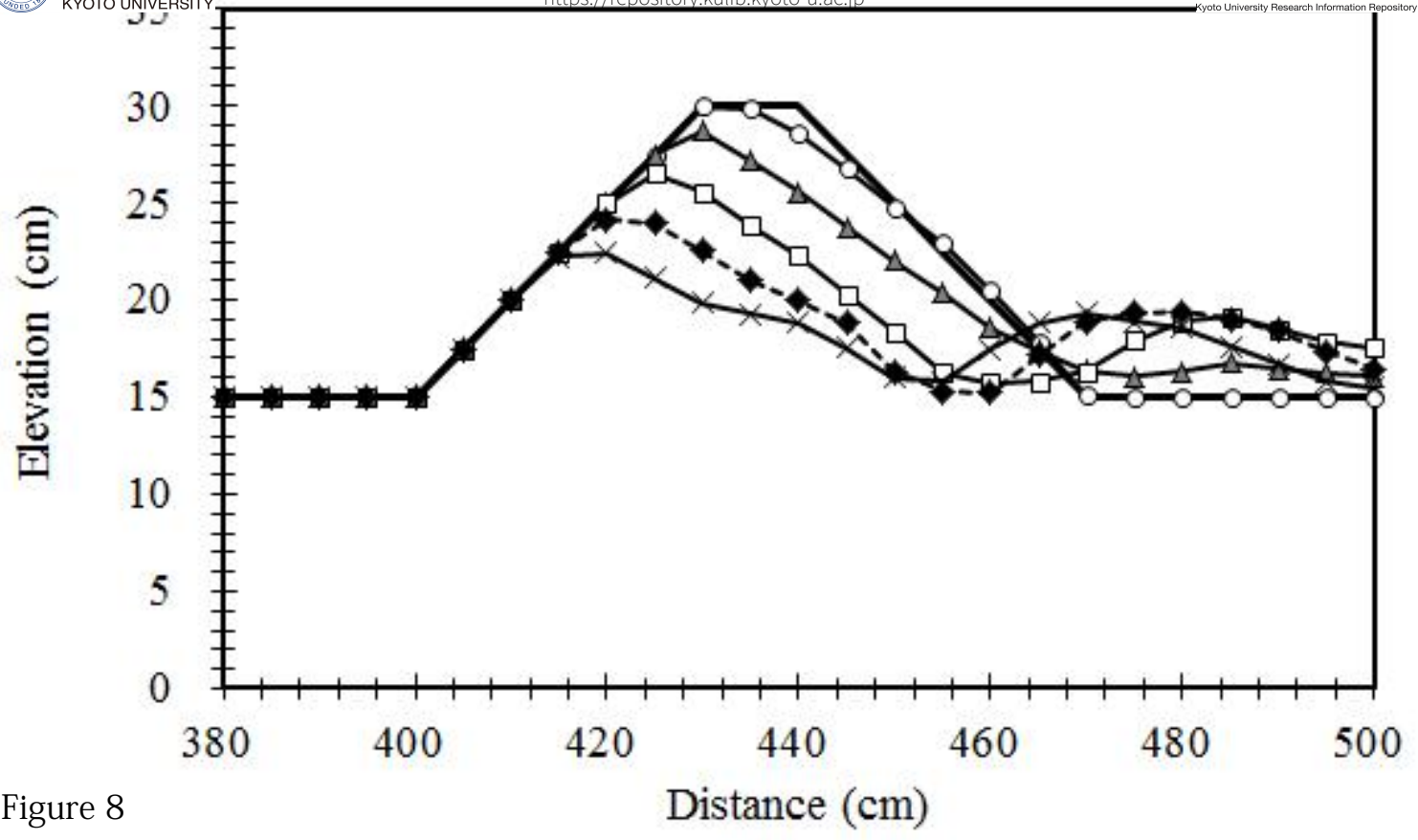


目都大学

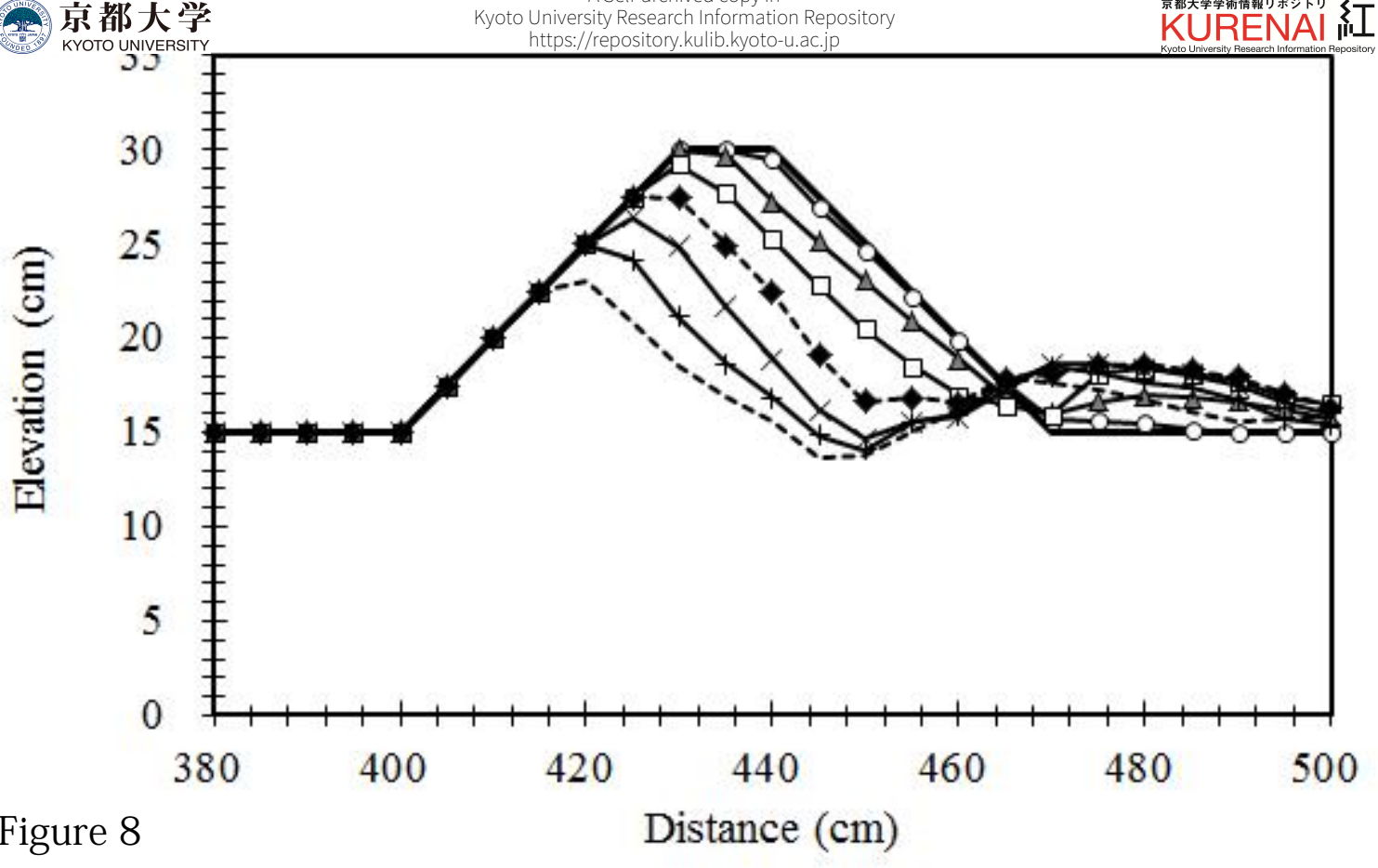



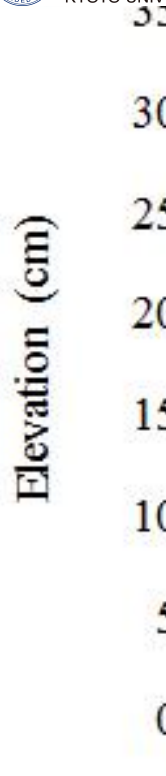

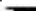

https://repository.kulib.kyoto-u.ac.jp KURENAI in

Figure 8

0 $380 \quad 400$

420

Distance $(\mathrm{cm})$ 


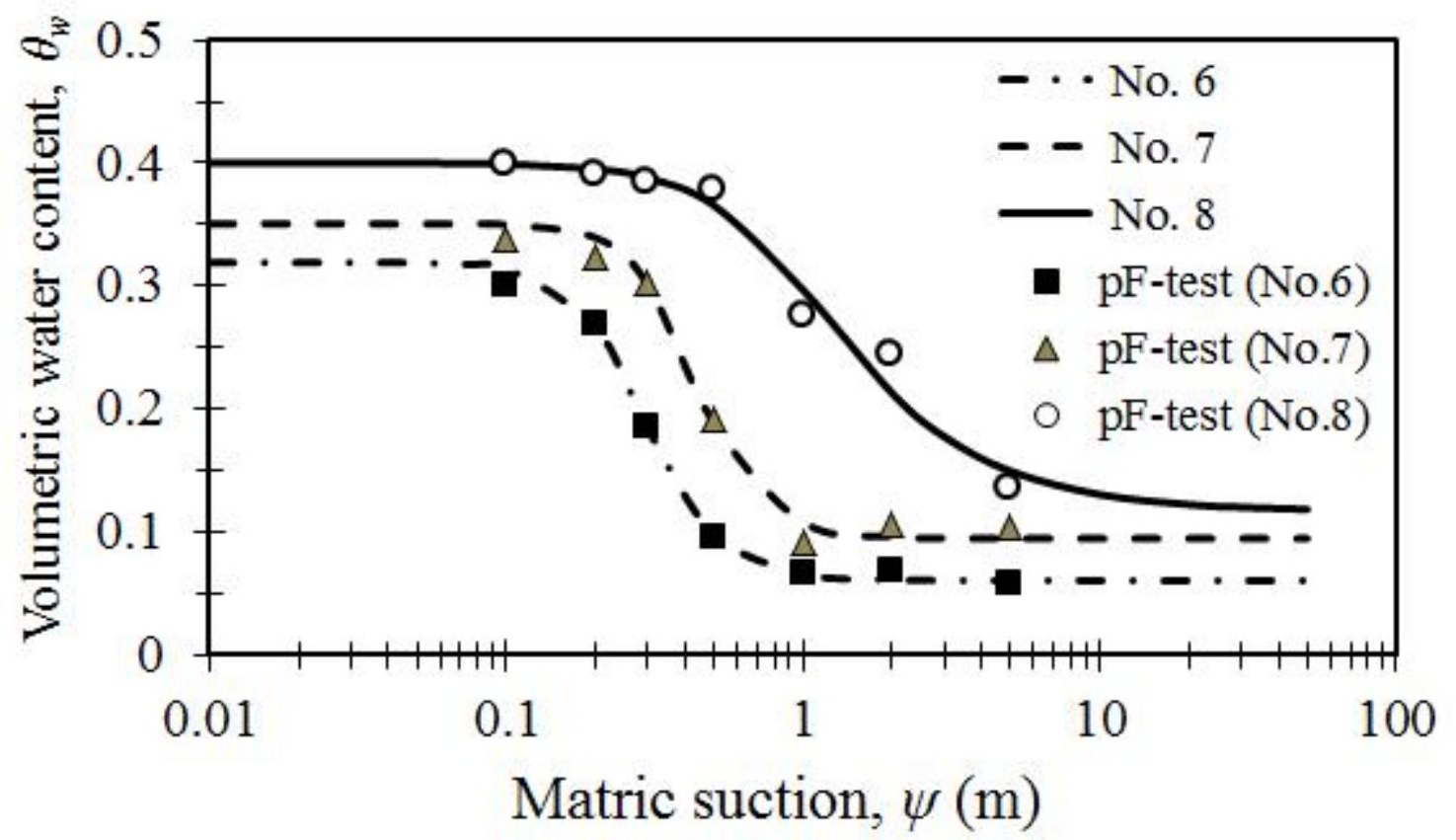




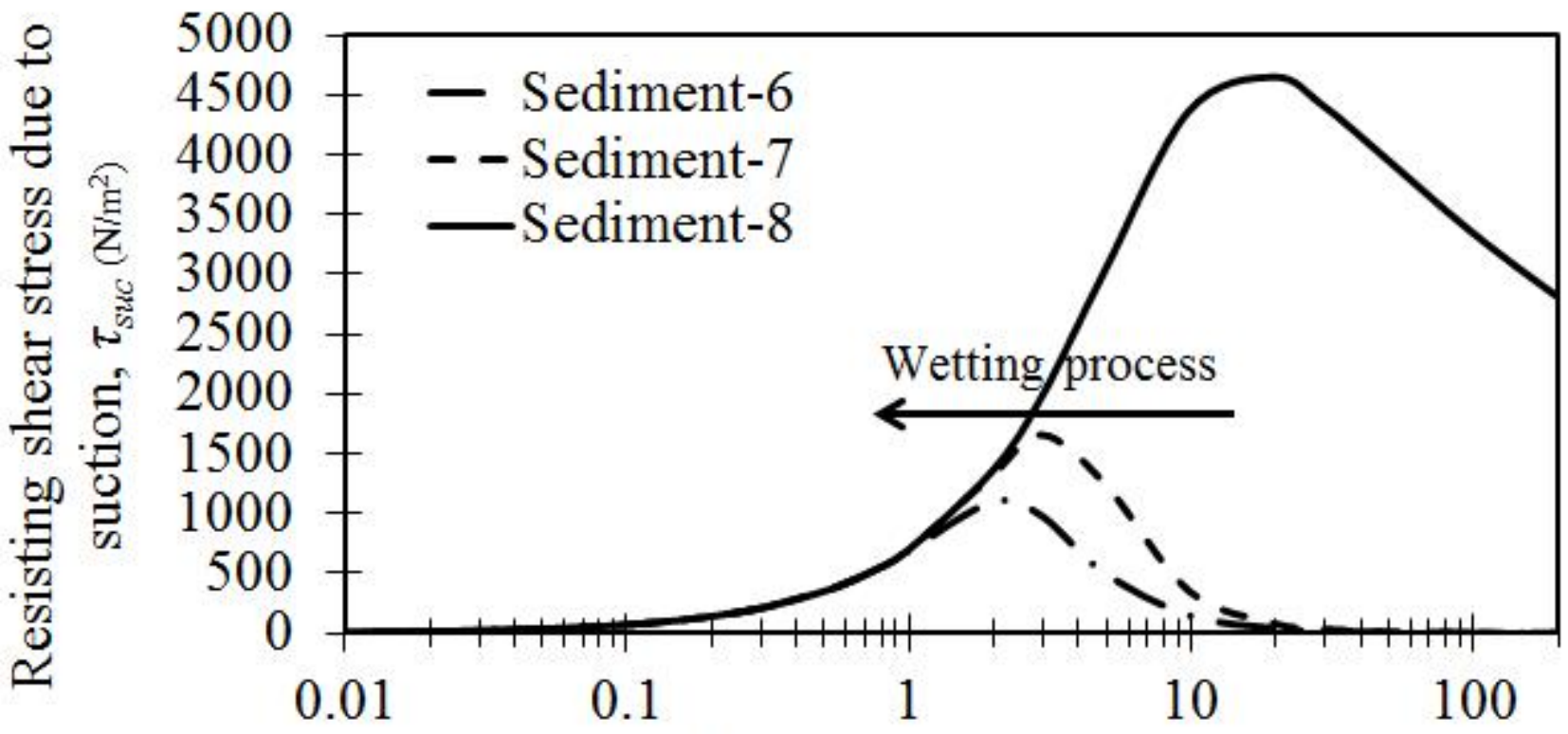

Matric suction, $\psi(\mathrm{m})$ 


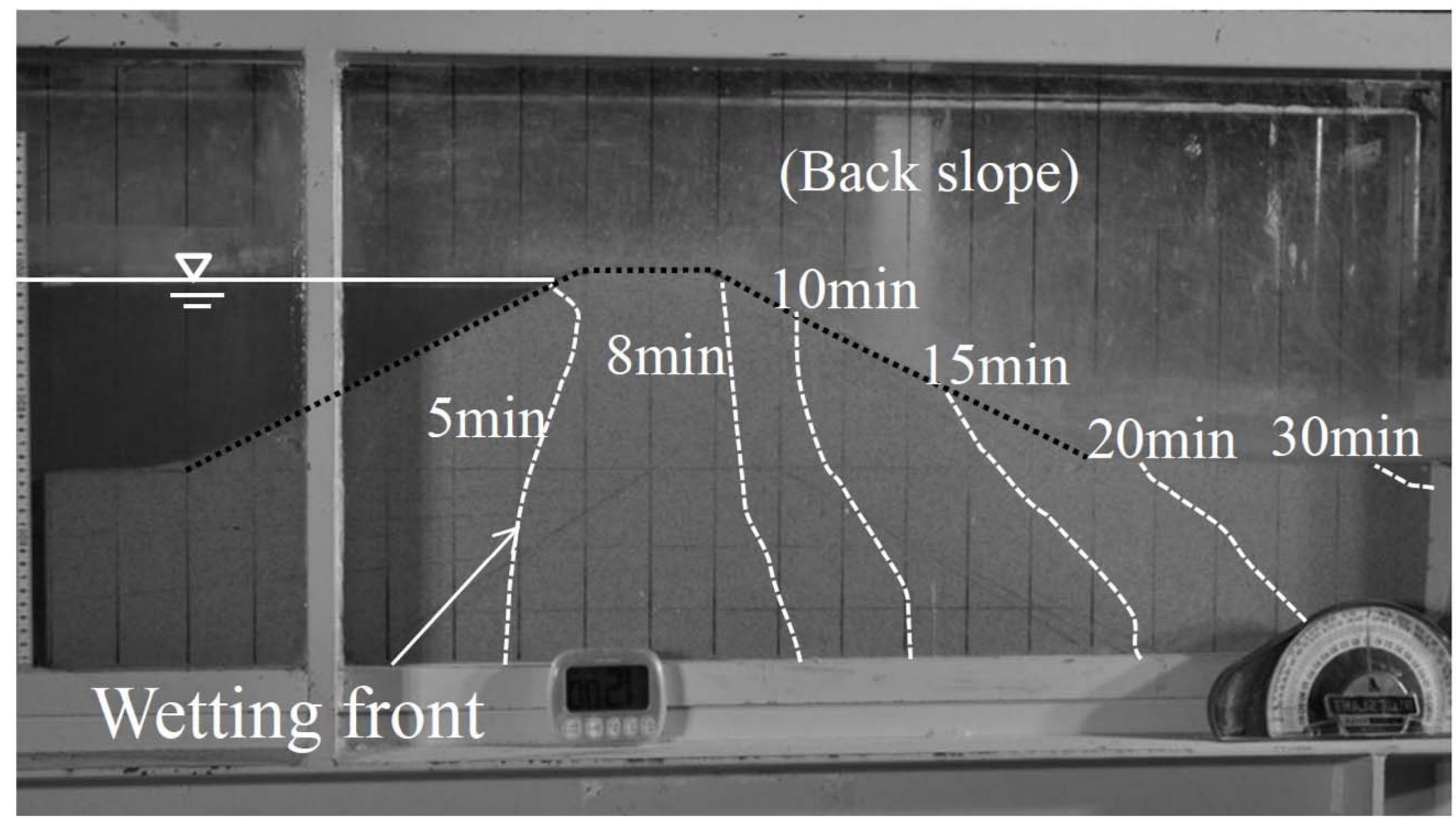

Figure $11(\mathrm{a})$ 


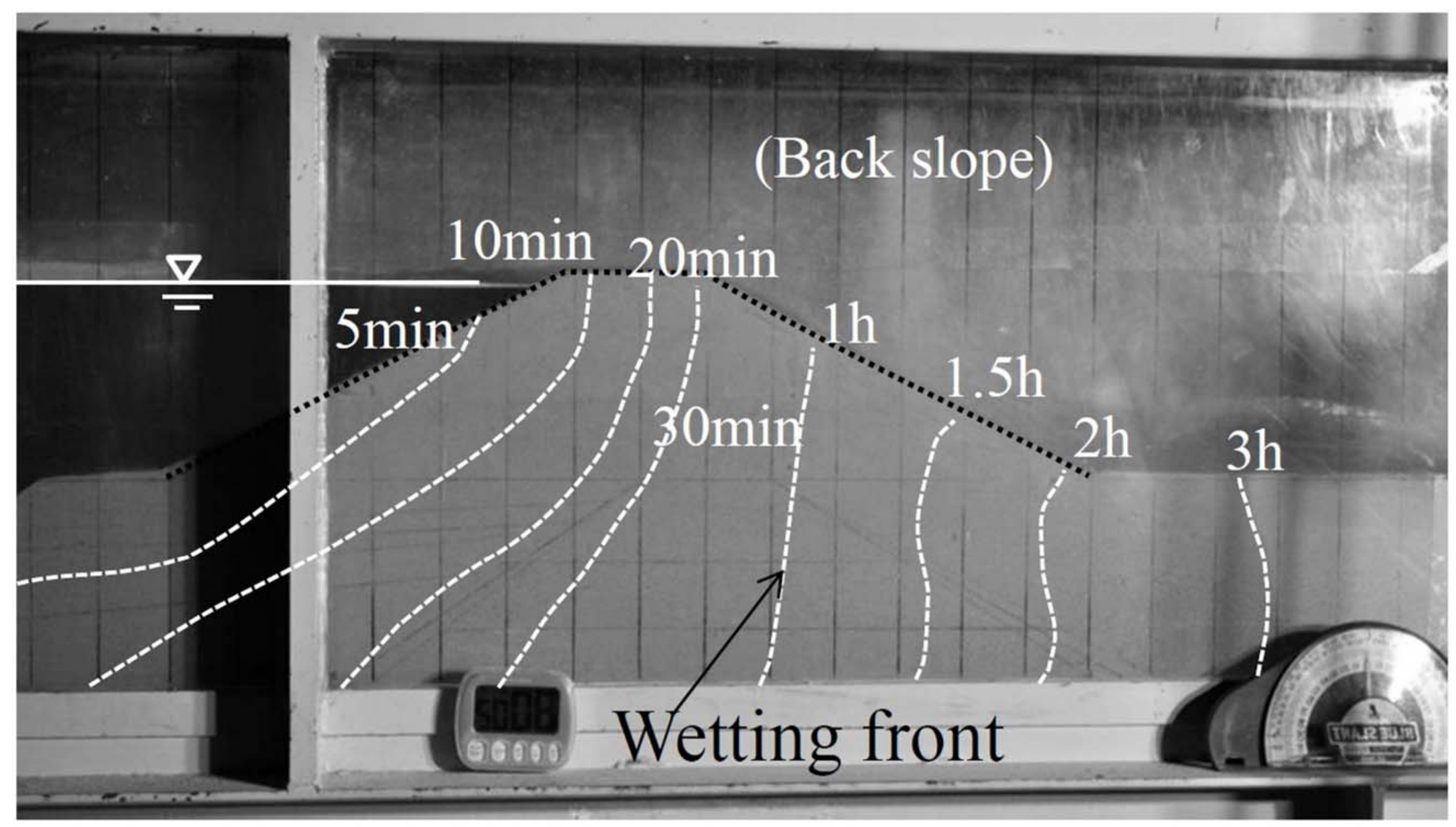

Figure $11(\mathrm{~b})$ 


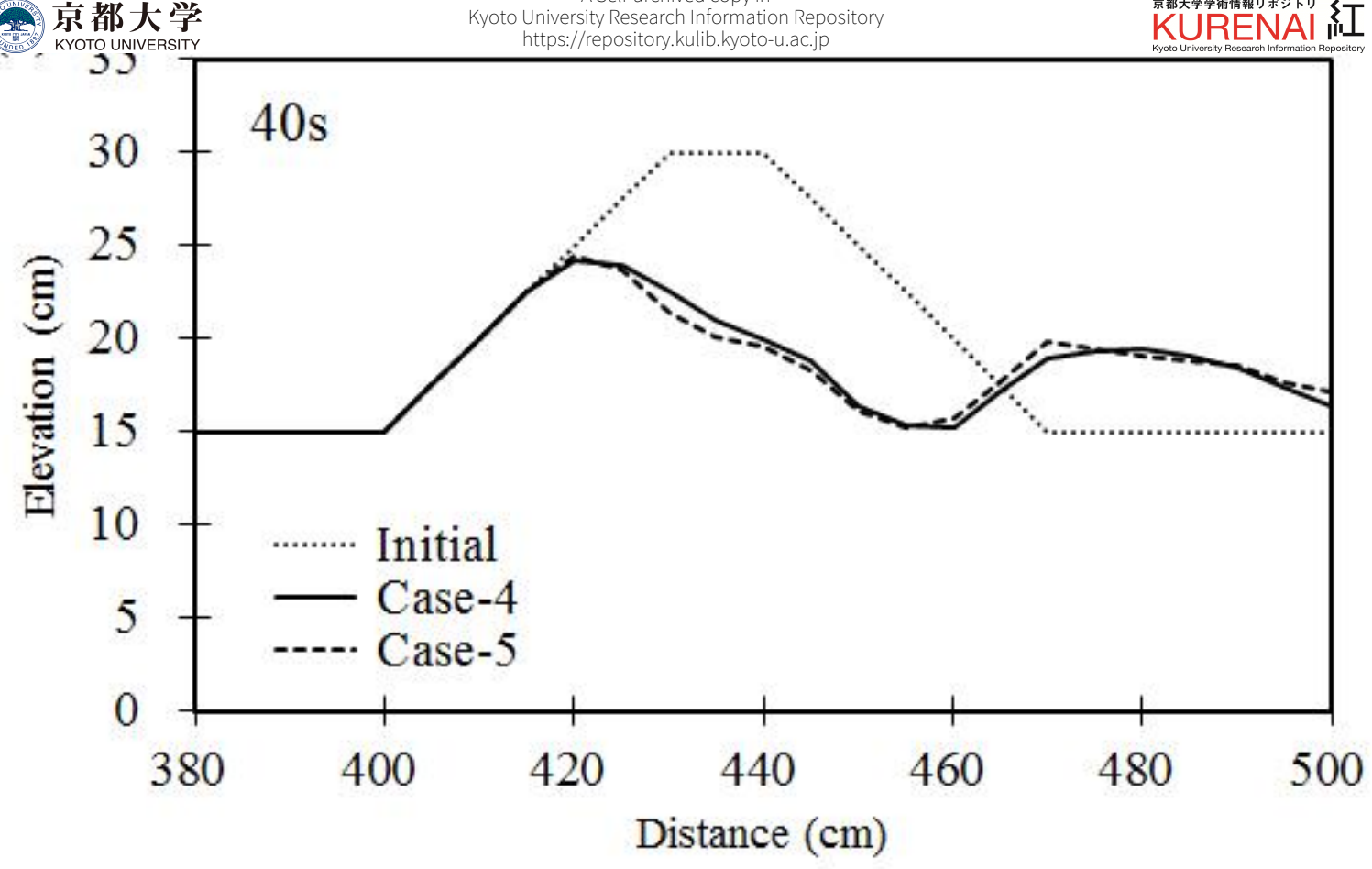

Figure 12 


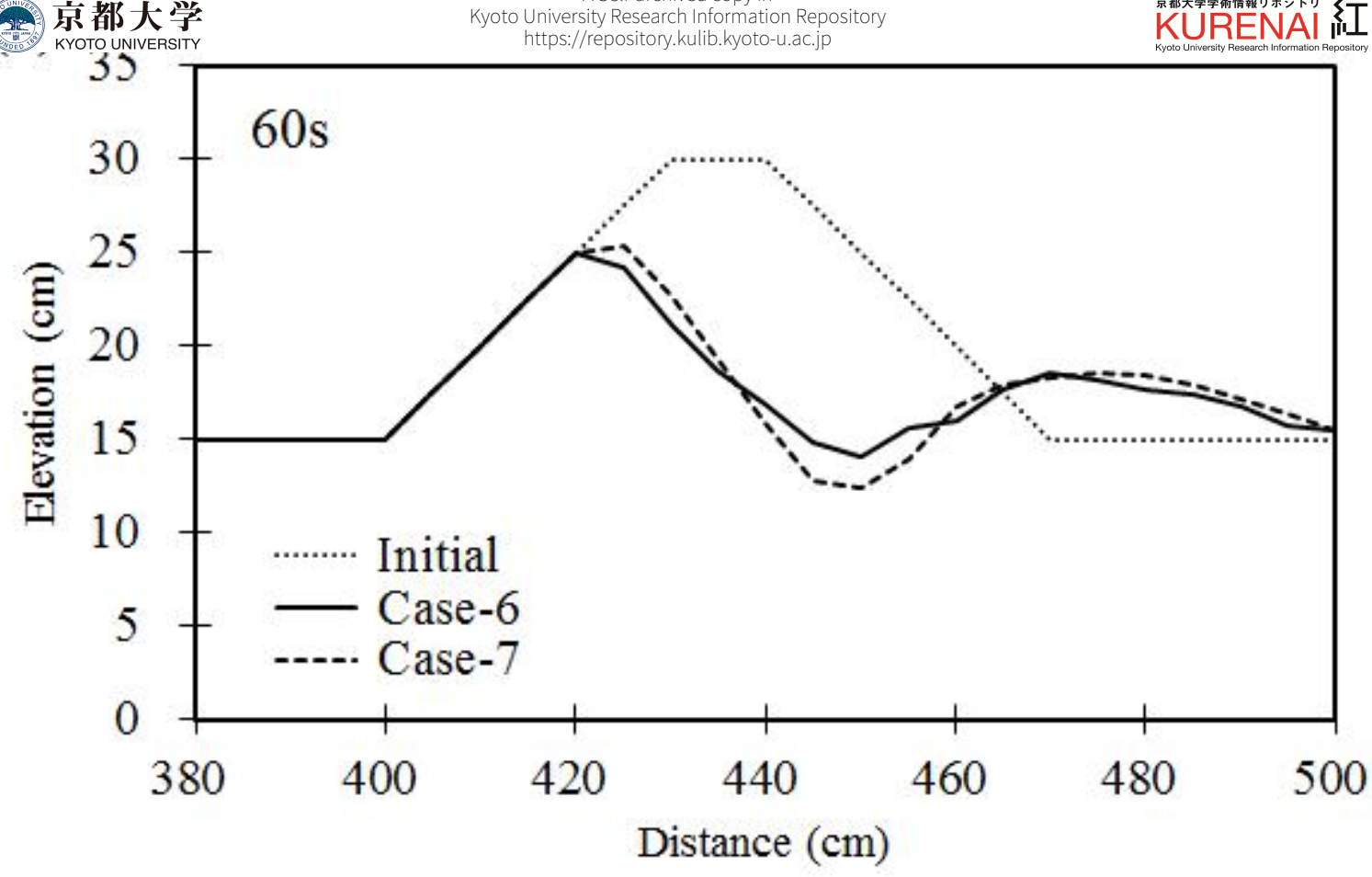

Figure 12 


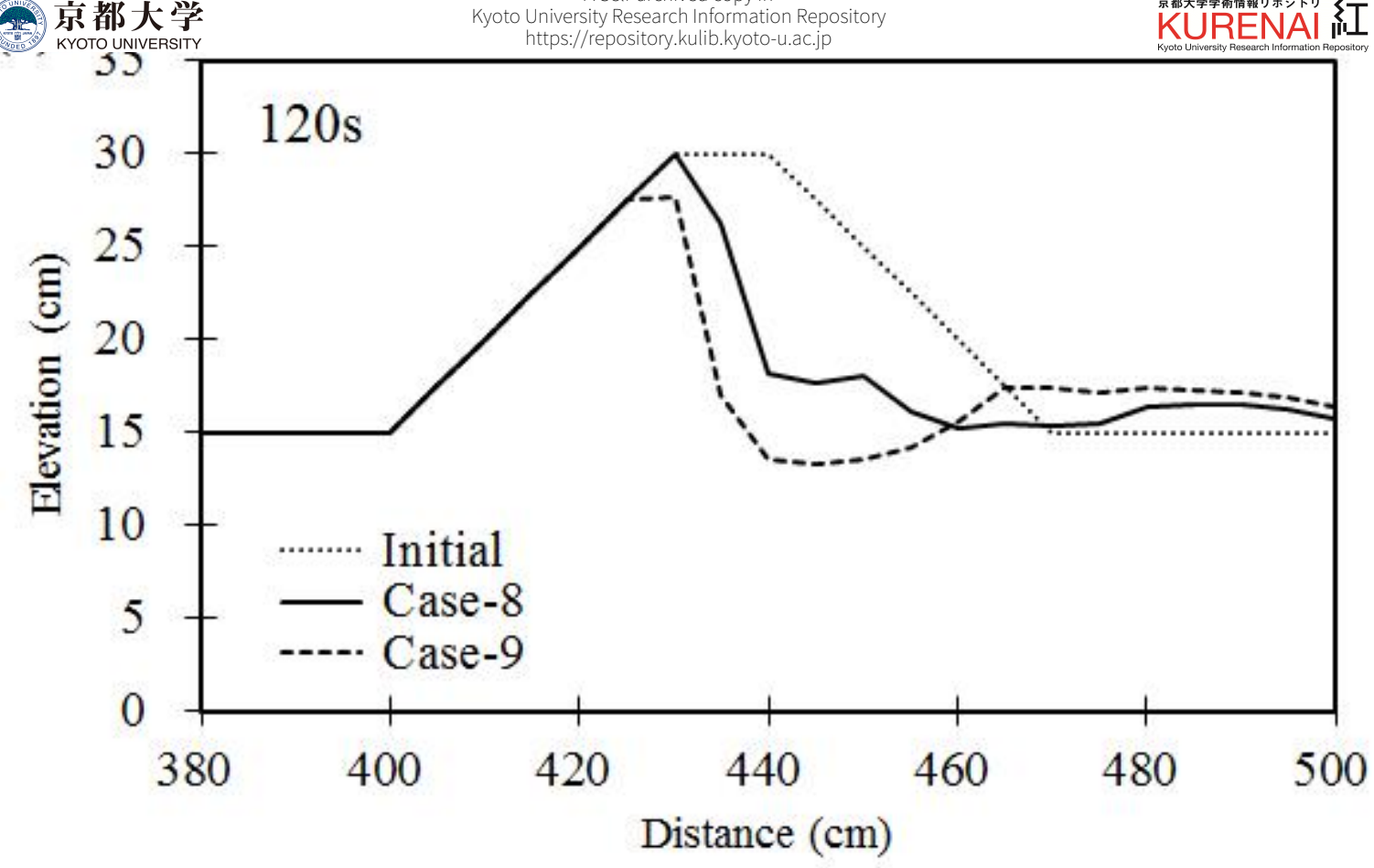

Figure 12 
京都大学

A Self-archived copy in

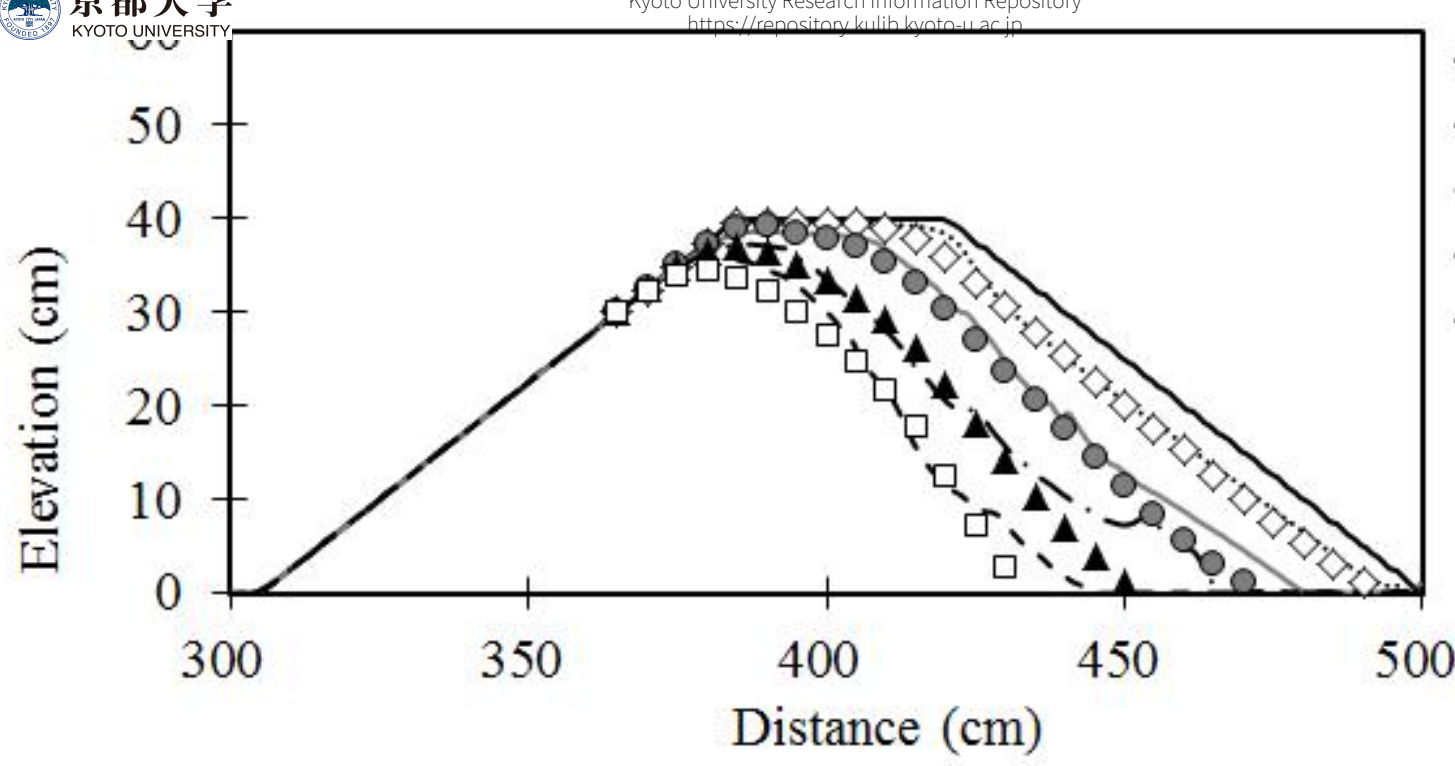

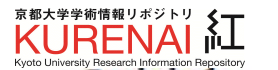

Initial sim-10s sim-20s

- - $-\operatorname{sim}-30 \mathrm{~s}$

- - - sim-40s

$\diamond$ exp-10s

- exp-20s

\ $\exp -30 \mathrm{~s}$

$\square$ exp-40s

Figure 13 
2 京都大学

A Self-archived copy in
Kyoto University Research Information Repository

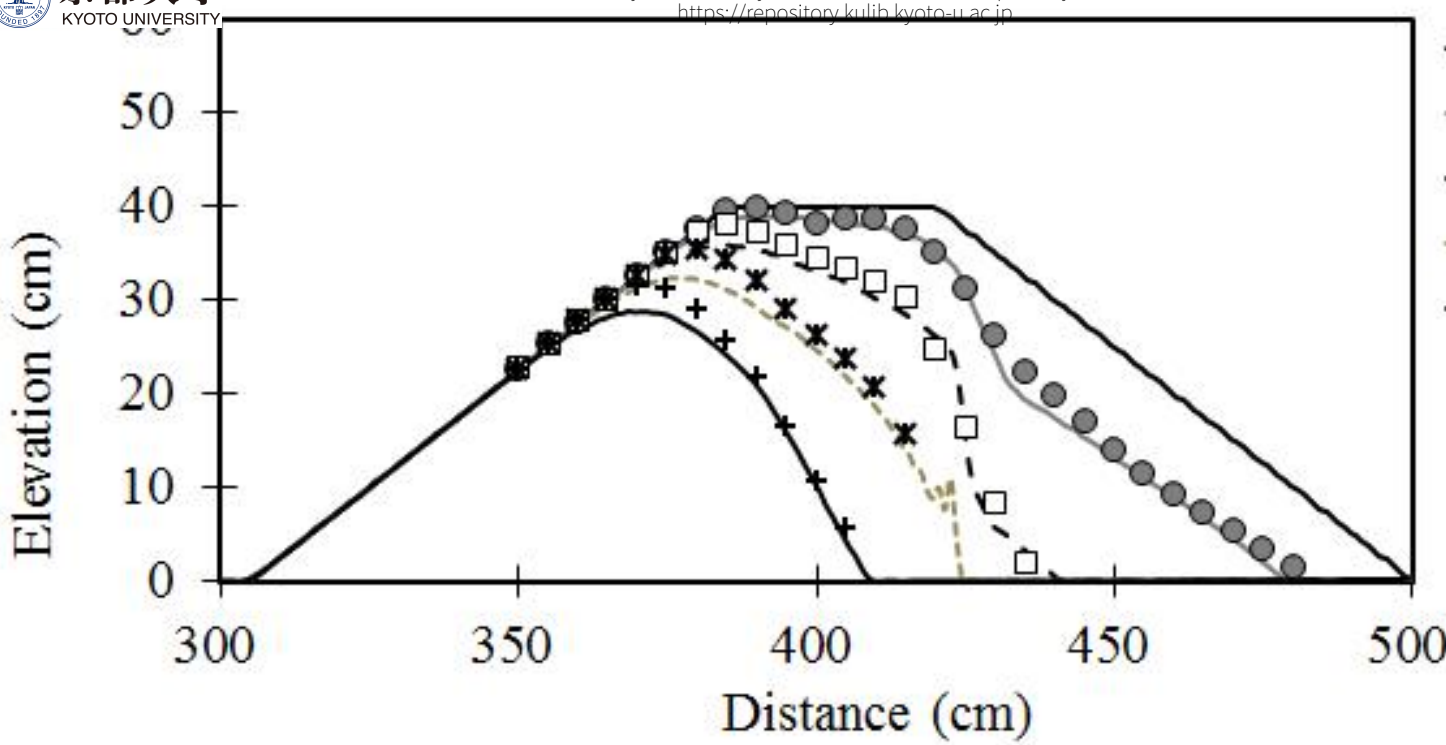

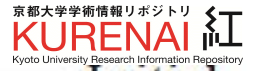
- Initial sim-20s

- - - sim-40s

-----sim-60s

$-\operatorname{sim}-80 \mathrm{~s}$

- exp-20s

$\square$ exp-40s

* exp-60s

+ exp-80s

Figure 13 
㘧大学

A Self-archived copy in
Kyoto University Research Information Repository

है

KYOTO UNIVERSITY

UNIVERSTY

50

40

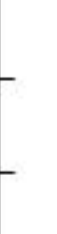

Kyoto University Research Information Repository

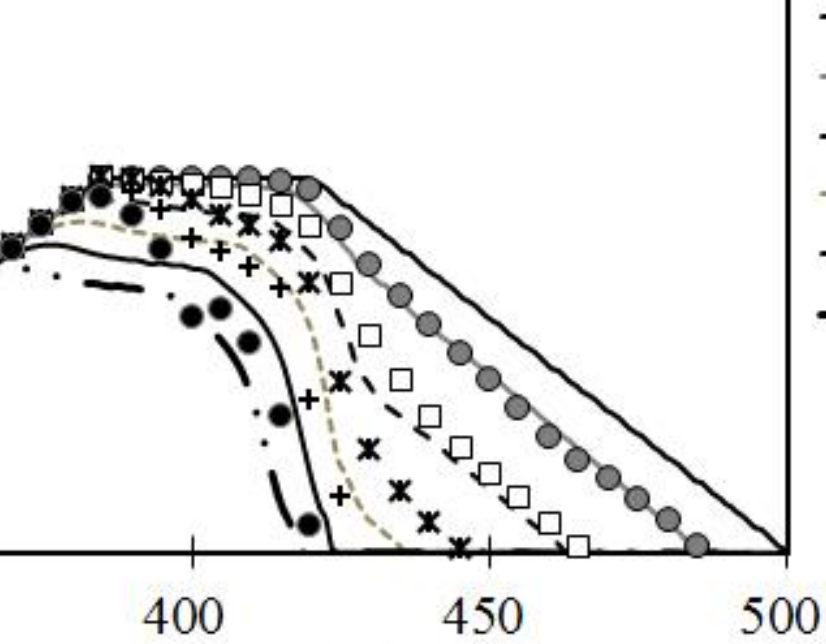

Distance $(\mathrm{cm})$

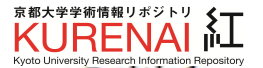

- Initial sim-20s

- - - sim- $40 \mathrm{~s}$

----sim-60s

$-\operatorname{sim}-80 \mathrm{~s}$

- $\cdot \operatorname{sim}-100 \mathrm{~s}$

- exp-20s

$\square$ exp-40s

$\times \exp -60 \mathrm{~s}$

+ exp-80s

- $\exp -100 \mathrm{~s}$

Figure 13 


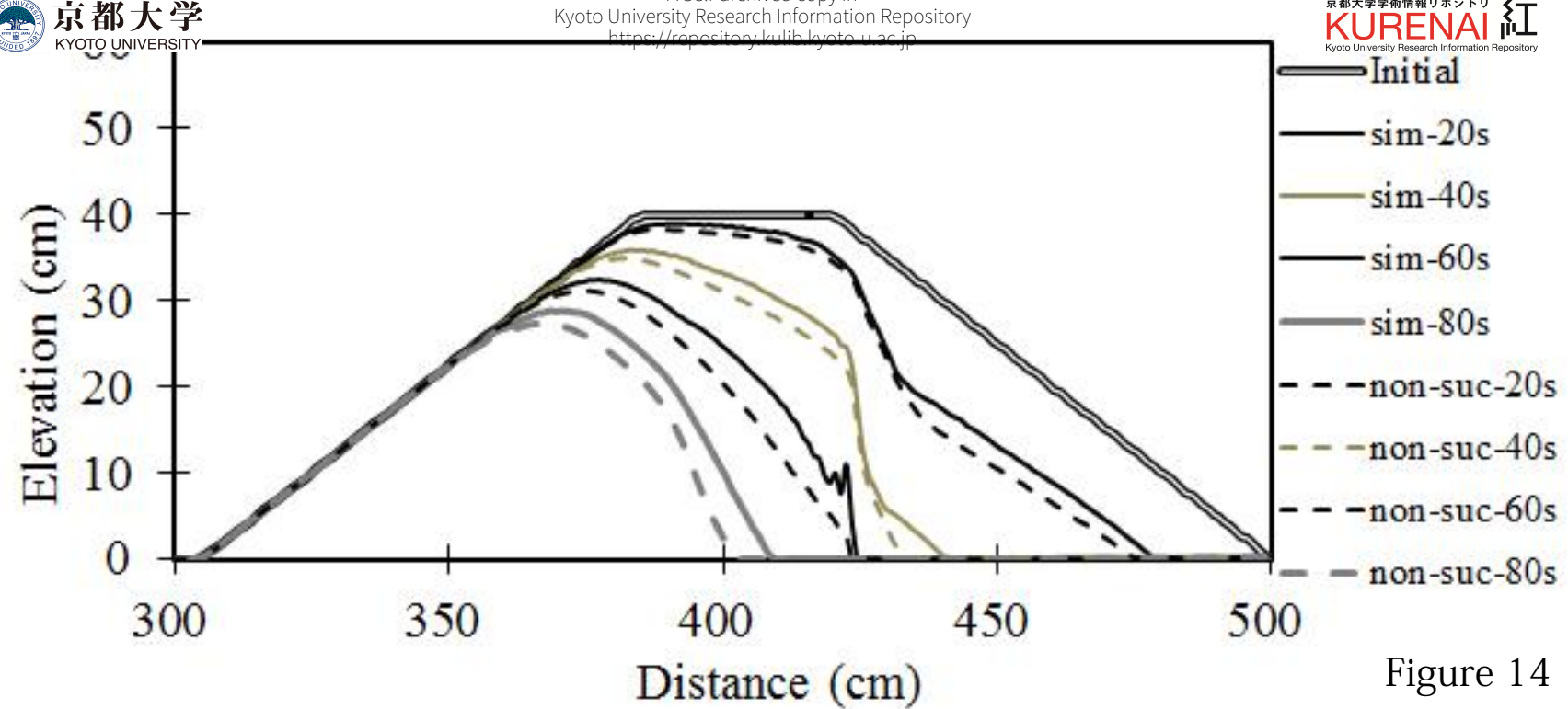




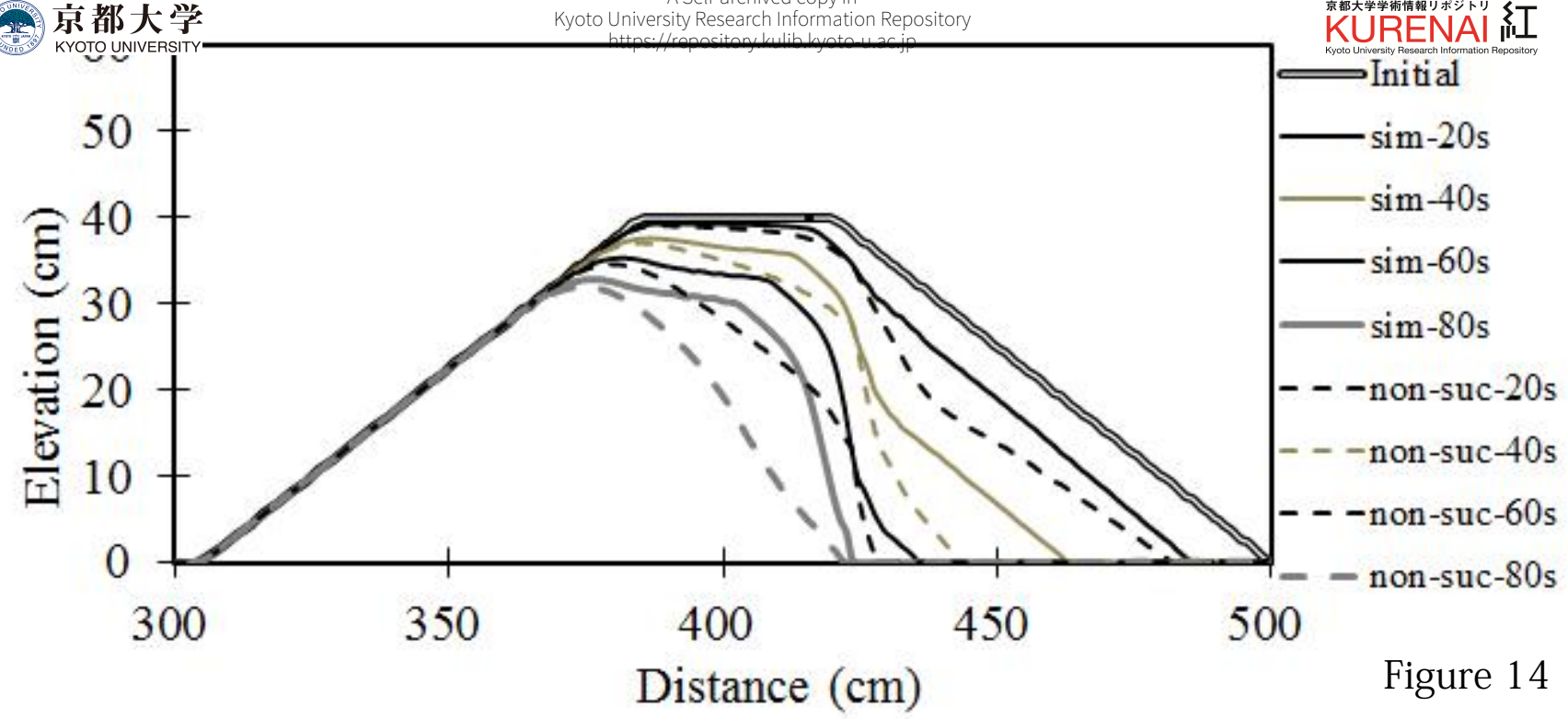


2. 京都大学

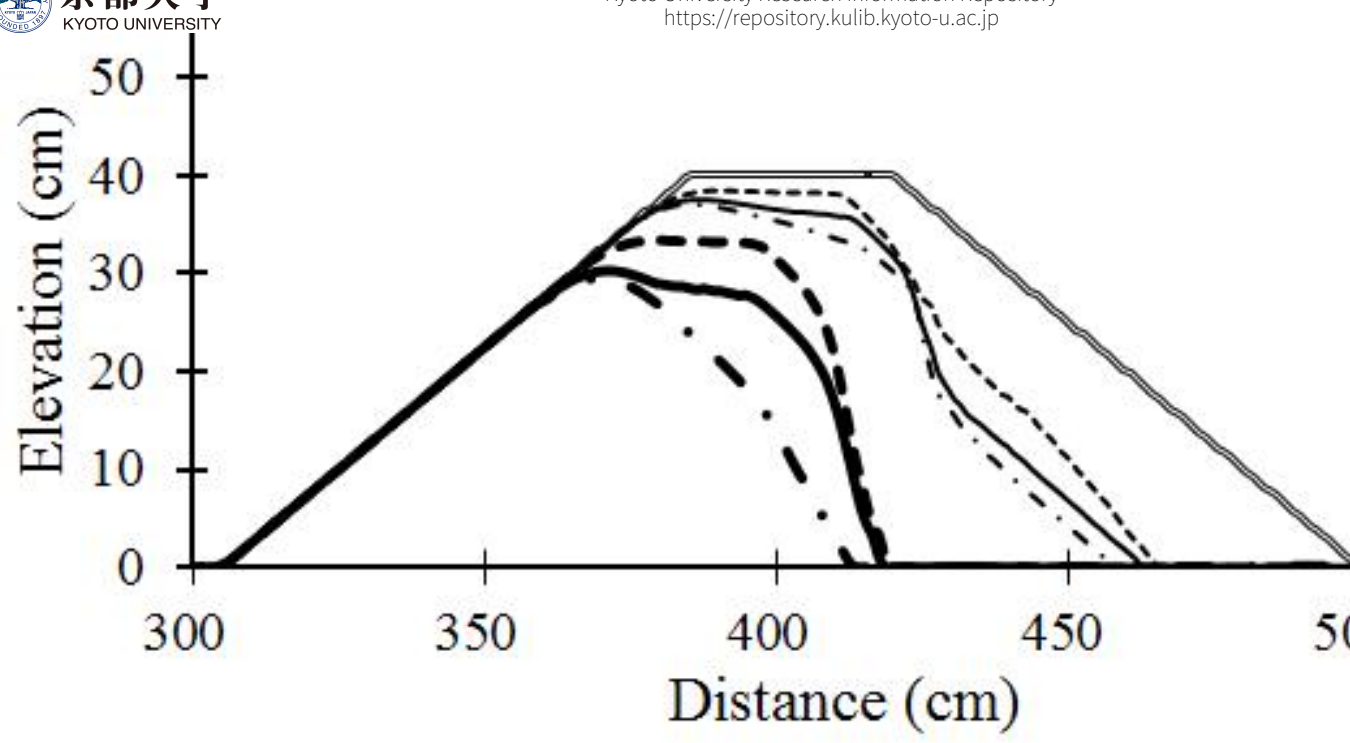

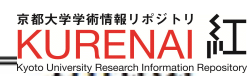
K1-40s K2-40s -. - K3-40s - - K $1-100 \mathrm{~s}$ $-\mathrm{K} 2-100 \mathrm{~s}$ - $\mathrm{K} 3-100 \mathrm{~s}$ 500

Figure 15 


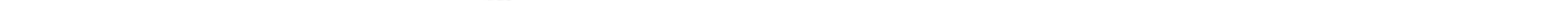

